\title{
Precision medicine: retrospective chart review and data analysis of 200 patients on dapsone combination therapy for chronic Lyme disease/ post-treatment Lyme disease syndrome: part I
}

This article was published in the following Dove Medical Press journal: International Journal of General Medicine

\section{Richard I Horowitz ${ }^{1,2}$ Phyllis R Freeman ${ }^{2}$ \\ 'Health and Human Services, Tick- Borne Disease Working Group, Washington, DC 2020 I USA; ${ }^{2}$ Hudson Valley Healing Arts Center, Hyde Park, NY 12538, USA}

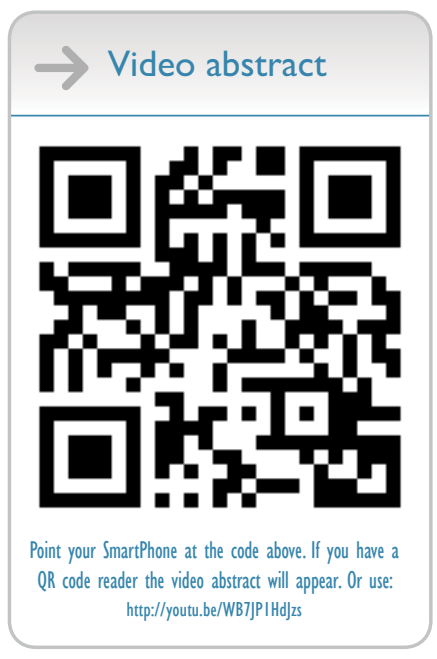

Correspondence: Richard I Horowitz Hudson Valley Healing Arts Center, 4232 Albany Post Road, Hyde Park, NY 12538, USA

$\mathrm{Tel}+\mathrm{I} 8452298977$

Fax + I 8452298930

Email medical@hvhac.com
Purpose: We collected data from an online survey of 200 of our patients, which evaluated the efficacy of dapsone (diaminodiphenyl sulfone, ie, DDS) combined with other antibiotics and agents that disrupt biofilms for the treatment of chronic Lyme disease/post-treatment Lyme disease syndrome (PTLDS). We also collected aggregate data from direct retrospective chart review, including laboratory testing for Lyme, other infections, and associated tick-borne coinfections. This helped us to determine the frequency of exposure to other infections/coinfections among a cohort of chronically ill Lyme patients, evaluate the efficacy of newer "persister" drug regimens like DDS, and determine how other infections and tick-borne coinfections may be contributing to the burden of chronic illness leading to resistant symptomatology.

Patients and methods: A total of 200 adult patients recruited from a specialized Lyme disease medical practice had been ill for at least 1 year. We regularly monitored laboratory values and participants' symptom severity, and the patients completed the online symptom questionnaire both before beginning treatment and after 6 months on DDS combination therapy (DDS CT). Paired-samples $t$-tests and Wilcoxon signed-rank nonparametric test were performed on each of eight major Lyme symptoms, both before DDS CT and after 6 months of therapy.

Results: DDS CT statistically improved the eight major Lyme symptoms. We found multiple species of intracellular bacteria including rickettsia, Bartonella, Mycoplasma, Chlamydia, Tularemia, and Brucella contributing to the burden of illness and a high prevalence of Babesia complicating management with probable geographic spread of Babesia WA1/duncani to the Northeast. Borrelia, Bartonella, and Mycoplasma species, as well as Babesia microti had variable manifestations and diverse seroreactivity, with evidence of persistence despite commonly prescribed courses of anti-infective therapies. Occasional reactivation of viral infections including human herpes virus 6 was also seen in immunocompromised individuals.

Conclusion: DDS CT decreased eight major Lyme symptoms severity and improved treatment outcomes among patients with chronic Lyme disease/PTLDS and associated coinfections. Keywords: Lyme disease, babesiosis, bartonella, tick-borne co-infections, Multiple Systemic Infectious Disease Syndrome, MSIDS, persister bacteria, immune deficiency

\section{Introduction}

Lyme disease is the number one vector-borne illness in the United States. There has been a $320 \%$ increase in the number of US counties affected within the past 20 years, 
as well as an alarming threefold increase in the number of vector-borne disease cases reported to public health authorities from 2004 to 2016. ${ }^{2}$ The May 1, 2018 edition of the Centers for Disease Control and Prevention's Morbidity and Mortality Weekly Report found that of the almost 650,000 reported cases during a 12-year period, over 491,000 were tick-borne and over 150,000 were mosquito-borne. ${ }^{3}$ Recently there was another $22 \%$ increase in tick-borne infections where "[c]ases of Lyme disease, anaplasmosis/ehrlichiosis, spotted fever rickettsiosis (including Rocky Mountain spotted fever [RMSF]), babesiosis, tularemia, and Powassan virus disease all increased - from 48,610 cases in 2016 to 59,349 cases in 2017."4

These numbers may not however adequately represent the true public health burden. The underreporting of tick-borne diseases is a well-established healthcare phenomenon, and some states like New York who "estimate" cases are not counted in the federal numbers. ${ }^{5}$ Those patients with symptoms of chronic Lyme disease, both diagnosed and undiagnosed, are also significantly contributing to the healthcare burden. They are known to be as functionally disabled as patients with chronic congestive heart failure according to prior NIH studies, ${ }^{6}$ with $42 \%$ of affected individuals reporting that they stopped working. ${ }^{7}$

The establishment of a new paradigm to account for why patients struggle with disabling symptoms after commonly prescribed treatments for chronic Lyme/post-treatment Lyme disease syndrome (PTLDS) is of vital importance based on the significant numbers of individuals contracting vector-borne diseases, including multiple Borrelia sensu lato species, relapsing fever borrelia, and other tick-borne infections. A chart review of a large cohort of chronically ill Lyme patients was therefore undertaken to better define the role of multiple variables on the 16-point Multiple Systemic Infectious Disease Syndrome (MSIDS) map and the role of overlapping infections/tick-borne coinfections in those suffering from resistant symptoms of chronic Lyme disease/PTLDS.

In part I of this observational study, we collected data from an online survey of 200 of our patients. They volunteered to participate in a study that evaluated the efficacy of diaminodiphenyl sulfone, that is, dapsone (DDS) combined with other antibiotics and agents that disrupt biofilms for the treatment of chronic Lyme disease/PTLDS. DDS combination therapy (DDS CT) had previously been published to be effective as a novel "persister" drug regimen for the treatment of chronic Lyme disease/PTLDS ${ }^{8}$ in 100 patients who had previously failed commonly prescribed antibiotic therapies.
We also collected aggregate data from direct retrospective chart review, which included laboratory testing for Lyme, other infections, and associated tick-borne coinfections. This helped us to determine the frequency of exposure to other infections/coinfections among a cohort of chronically ill Lyme patients, evaluate the efficacy of newer "persister" drug regimens like DDS, and determine how other infections and tick-borne coinfections may be contributing to the burden of chronic illness leading to resistant symptomatology.

\section{Patients and methods}

\section{Participants}

Participants included in this retrospective chart review $(\mathrm{N}=200)$ were adults recruited from a specialized Lyme disease medical practice using email and telephone contacts. Although situated in the Northeastern United States, the medical practice attracts patients from all over the world. Of 200 participants, 67 (33.5\%) were male, 133 (66.5\%) were female. Age ranged from 18 to 84 years $(M=52.04$, $\mathrm{SD}=16.66)$. Out of 200 participants, four (2\%) were Asian (Non-Hispanic), while the rest were White (non-Hispanic). Participants were mostly from the United States $(\mathrm{N}=193)$, which was divided into demographic regions: West Coast $(\mathrm{N}=1)$, Midwest $(\mathrm{N}=16)$, East Coast (North) $(\mathrm{N}=155)$, East Coast (South) $(\mathrm{N}=20)$, and Other (Hawaii) $(\mathrm{N}=1)$.

The majority of patients enrolled in the study had been ill for at least 1 year and had been treated by multiple healthcare providers failing traditional antibiotic therapy for Lyme disease, which included but was not limited to tetracyclines, macrolides, penicillins, and cephalosporins. Potential participants were sent an email invitation containing a link to the online survey. After clicking the link, the participants viewed a page that explained the purpose of the survey and provided information necessary for them to make an informed decision about whether to participate or not. All survey participants were identifiable in order to compare their survey responses against their clinical record.

\section{Methodology}

Institutional Review Board approval was not required for this research since this was a retrospective review of patients' charts who were previously undergoing treatment for tick-borne illness under the care of the first author. After signing informed consent forms that outlined the proposed benefits and potential risks of our study, patients volunteered to enroll in a preliminary DDS trial at our medical center based on the drug's action on "persister" bacteria. ${ }^{9-12}$ There were two treatment arms: those patients on a tetracycline, 
rifampin, and DDS and those who were also placed on a cephalosporin (cefuroxime axetil or cefdinir) or a macrolide (clarithromycin or azithromycin). The choice of treatment was based on their prior clinical response to these medications (cephalosporins and or macrolides) and/or their coinfection status. All patients were placed on at least three different probiotics for gastrointestinal (GI) support, with regular laboratory monitoring of complete blood counts (CBCs), comprehensive metabolic profiles (CMPs), and methemoglobin levels before, during, and after DDS therapy.

Blood testing for Lyme disease and coinfection status were conducted using several Clinical Laboratory Improvement Amendments-certified national reference laboratories (Quest Diagnostics, Secaucus, NJ, USA; LabCorp, Burlington, NC, USA; BioReference, Elmwood Park, NJ, USA; and AccuReference Medical Lab, Wappingers Falls, NY, USA), local state laboratories (ie, Sunrise Medical Laboratories, Hicksville, NY, USA; NorDx, Scarborough, ME, USA; and Affiliated Laboratory Inc., Rutland, VT, USA), several hospital-based laboratories, and specialty laboratories for tick-borne diseases (Imugen, Norwood, MA, USA; IgeneX, Palo Alto, CA, USA; MDL Laboratory, Hamilton Township, NJ, USA; The State University at New York at Stony Brook Lyme Disease Laboratory, Stony Brook, NY, USA; Milford Molecular Diagnostics, Milford, CT, USA; Galaxy Diagnostics, Morrisville, NC, USA; and Immunosciences Lab Inc, Los Angeles, CA, USA). More than one laboratory was used for each patient depending on the laboratory capability, patient insurance, and availability in their home state (Galaxy Diagnostics was not available in NY).

We monitored participants' symptoms at each consultation (6-8 weeks), and the patients completed the online symptom questionnaire both before beginning treatment and after 6 months on DDS CT. The length of the trial varied, but those patients who continued to show clinical improvement remained on DDS CT after the 6-month period until they reached a plateau with no further improvement in symptoms. Paired-samples $t$-tests were performed on each of eight major Lyme symptoms with pre-DDS and DDS conditions, along with a Wilcoxon signed-rank nonparametric test to evaluate the small range of severity ratings.

Rigorous patient safeguards were in place, and each participant received detailed instructions that outlined the need for blood test every 3 weeks, dietary guidelines, and the name and phone number of the medical center's head nurse if anyone had questions or medical issues. Email address of a medical staff as well as an emergency beeper number were also provided. Medication refills were only given if blood testing was up to date, and patients were contacted by the nursing staff if any abnormal laboratory results required a change in medication or for an updated appointment.

Surveys were conducted in office, online, and via telephone to gather patient information. The symptom questionnaire that the patients have completed is derived from a larger validated Lyme questionnaire ${ }^{13}$ and the work of Shadick et al. ${ }^{14}$ Symptom severity of eight symptoms was gathered both before beginning DDS CT and after 6 months of treatment, following a protocol from our previous study by Horowitz and Freeman on DDS. ${ }^{8}$

Symptoms measured were:

1. Fatigue and/or tiredness

2. Muscle and/or joint pain

3. Headache

4. Tingling and/or numbness and/or burning of extremities

5. Sleep problems

6. Forgetfulness and/or brain fog

7. Difficulty with speech and/or writing

8. Day sweats and/or night sweats and/or flushing

Participants rated the severity of these symptoms both before DDS CT and after 6 months, to examine whether DDS CT decreased the severity of these symptoms. Data were gathered using a 5-point severity scale wherein patients indicated the severity of each symptom, where 1 represented no symptom, and 5 represented the most severe.

\section{Inclusion criteria}

All 200 patients in our retrospective chart review met the criteria for a clinical diagnosis of Lyme disease supported by a physician documented erythema migrans (EM) rash and/ or positive laboratory testing, including a positive ELISA/ enzyme immunoassay, and/or C6 ELISA, immunofluorescent antibody (IFA), Centers for Disease Control and Prevention (CDC) positive IgM and/or IgG Western blot (WB), PCR, Borrelia-specific bands $(23,31,34,39,83 / 93)$ on a $\mathrm{WB},{ }^{15}$ and/or positive ELISpot (lymphocyte transformation test [LTT]). These patients had either failed or had an inadequate response to prior antibiotic therapy and/or had relapsed with persistent symptoms after stopping anti-infective therapy.

\section{Exclusion criteria}

Patients under the age of 18 years, having a known allergy to DDS or any medication used in the trial, and/or having significant laboratory abnormalities including a pre-trial anemia were excluded from our study. 


\section{Surveys included}

Surveys with questions regarding DDS status (currently or previously taking the drug), DDS dosage, coinfections, other drugs, side effects, and symptom severity for common Lyme symptoms before and after at least 6 months of DDS treatment (the full survey is available on request from the authors) were included.

\section{Results}

DDS status consisted of $53.70 \%$ currently taking DDS for at least 6 months, and $46.30 \%$ no longer taking DDS. Dosages included $25 \mathrm{mg}$ (12\%), $50 \mathrm{mg}$ (23.5\%), $75 \mathrm{mg}$ $(12 \%)$, and $100 \mathrm{mg}(51.5 \%)$. DDS treatment is occasionally pulsed - instead of taking the medication daily, it can be taken 3 days a week, or every other day, and so on, depending on the severity of Herxheimer reactions with regular use. About $20.5 \%$ of participants indicated that their DDS treatment was pulsed. Reasons for stopping DDS treatment were "My symptoms improved" $(\mathrm{N}=22)$, "I had an adverse reaction" ( $\mathrm{N}=46)$, and "I switched to a different protocol" ( $\mathrm{N}=22)$.

The percent severity rating for each symptom in predapsone (pre-DDS) and DDS-treated patients are available in Table 1. Thirty-five cases were missing both pre-DDS and DDS severity data or either one. These cases were removed from this table and from $t$-test analyses leaving symptom severity data for 165 patients.

In order to analyze this, paired-samples $t$-tests were performed on each symptom with pre-DDS and DDS conditions of: fatigue and/or tiredness: $t(164)=10.69, P<0.001$, muscle and/or joint pain: $t(164)=8.13, P<0.001$, headache: $t(164)=5.35, P<0.001$, tingling and/or numbness and/or burning of extremities: $t(164)=6.71, P<0.001$, sleep problems: $t(164)=6.17, P<0.001$, forgetfulness and/or brain fog: $t(164)=9.84, P<0.001$, difficulty with speech and/or writing: $t(164)=8.70, P<0.001$, and day sweats and/or night sweats and/or flushing: $t(164)=8.36, P<0.001$.

A Wilcoxon signed-rank nonparametric test (which was run due to the small range of severity ratings) showed a statistically significant change in severity ratings of the same eight symptoms for pre-DDS and DDS conditions. Results indicated that for fatigue and/or tiredness: $Z=-8.624$, $P<0.001$, muscle and/or joint pain: $Z=-7.295, P<0.001$, headache: $Z=-5.587, P<0.001$, tingling and/or numbness and/or burning of extremities: $Z=-7.302, P<0.001$, sleep problems: $Z=-6.363, P<0.001$, forgetfulness and/or brain fog: $Z=-8.169, P<0.001$, difficulty with speech and/or writing:
Table I Percent severity ratings before dapsone and with dapsone combination therapy

\begin{tabular}{|c|c|c|c|}
\hline Symptoms & Severity rating & Pre-DDS* (\%) & DDS* (\%) \\
\hline \multirow[t]{5}{*}{ Fatigue } & I & 3 & 9.1 \\
\hline & 2 & 9.1 & 26.7 \\
\hline & 3 & 25.5 & 37 \\
\hline & 4 & 39.4 & 20 \\
\hline & 5 & 23 & 7.3 \\
\hline \multirow[t]{5}{*}{ Muscle } & I & 12.7 & 18.8 \\
\hline & 2 & 13.3 & 34.5 \\
\hline & 3 & 30.3 & 27.9 \\
\hline & 4 & 31.5 & 13.9 \\
\hline & 5 & 12.1 & 4.8 \\
\hline \multirow[t]{5}{*}{ Headache } & I & 35.8 & 40 \\
\hline & 2 & 19.4 & 37.6 \\
\hline & 3 & 24.8 & 12.7 \\
\hline & 4 & 12.1 & 5.5 \\
\hline & 5 & 7.9 & 4.2 \\
\hline \multirow[t]{5}{*}{ Tingling } & I & 26.1 & 37 \\
\hline & 2 & 24.8 & 35.8 \\
\hline & 3 & 27.9 & 15.8 \\
\hline & 4 & 13.3 & 7.9 \\
\hline & 5 & 7.9 & 3.6 \\
\hline \multirow[t]{5}{*}{ Sleep } & I & 17.6 & 24.8 \\
\hline & 2 & 18.8 & 29.7 \\
\hline & 3 & 25.5 & 24.2 \\
\hline & 4 & 21.8 & 11.5 \\
\hline & 5 & 16.4 & 9.7 \\
\hline \multirow[t]{5}{*}{ Forgetfulness } & $I$ & 9.1 & 20 \\
\hline & 2 & 13.3 & 34.5 \\
\hline & 3 & 30.3 & 23.6 \\
\hline & 4 & 28.5 & 13.3 \\
\hline & 5 & 18.8 & 8.5 \\
\hline \multirow[t]{5}{*}{ Speech } & 1 & 23.6 & 35.2 \\
\hline & 2 & 23 & 33.9 \\
\hline & 3 & 29.1 & 18.8 \\
\hline & 4 & 15.2 & 9.1 \\
\hline & 5 & 9.1 & 3 \\
\hline \multirow[t]{5}{*}{ Sweats } & 1 & 33.9 & 50.3 \\
\hline & 2 & 17.6 & 31.5 \\
\hline & 3 & 23 & 12.7 \\
\hline & 4 & 15.8 & 4.2 \\
\hline & 5 & 9.7 & 1.2 \\
\hline
\end{tabular}

Notes: $* \mathrm{~N}=165$. For each symptom, we see larger percentages for moderate or very severe ratings in the "pre" column, and those numbers shift over to none/mild/ moderate in the "DDS" column. These results indicate that dapsone combination therapy decreased severity of all eight symptoms.

Abbreviations: DDS, dapsone; Pre-DDS, pre-dapsone.

$Z=-7.873, P<0.001$, day sweats and/or night sweats and/or flushing: $Z=-8.081, P<0.001$.

These results further confirm that patients had a significant change in all eight chronic Lyme symptoms (Table 1).

We used two antibiotic combinations (these were the only combinations with similar group sizes, an assumption which 
must be met to do statistical analyses) to evaluate which combinations were the most effective:

1. DDS and a tetracycline with rifampin

2. DDS and a tetracycline with rifampin and a cephalosporin or a macrolide

(Most people were on rifampin, having one group with rifampin and another without would have given us grossly disproportionate group sizes).

There was no significant difference between the two groups, and both groups were effective in decreasing symptomatology. Further detailed data analysis will be necessary to determine if the addition of a cephalosporin and/or a macrolide temporarily improved symptoms (we often rotate antibiotics during the clinical course based on a patient's response). Unpublished scientific research done by Dr Eva Sapi's team at the University of New Haven evaluated DDS CTs in culture, and their effect on lowering Borrelia biofilm mass. These results were presented as a poster presentation at the ILADS 16th International Lyme Conference in 2016 in Boston ${ }^{16}$ and showed that DDS combined with doxycycline, rifampin and stevia was the most effective three drug/ herbal biofilm combination therapy, confirmed in our clinical study. Further translational clinical research, moving from the laboratory to the bedside will be necessary however to evaluate the efficacy of one regimen over another, especially in patients with associated coinfections. We were also not able to differentiate changes in symptom outcome based on different DDS doses, due to inadequate numbers of individuals in each dosage group.

Before rating the severity of their symptoms via questionnaire, patients were asked for a pre-DDS and DDS "Percent Normal" (on a 100-point scale) apart from evaluating their eight hallmark symptoms of Lyme disease. These data come from symptom ratings collected via an online Surveymonkey. com questionnaire. (https://www.surveymonkey.com/). Success in the DDS trial was operationally defined as improvement in percent of normal after 6 months on DDS. Failure was operationally defined as remaining the same or worsening of percentage of normal after at least 6 months of DDS CT. A paired-samples $t$-test demonstrates a significant difference from pre-DDS to DDS conditions: $t(180)=12.83, P<0.001$ (pre-M=51.34\%, DDS M=65.85\%). Of 181 participants who gave both pre-DDS and DDS percentage scores, 14 participants reported feeling worse currently than they did before the DDS, 22 participants reported no difference, while all other participants (145) currently reported a higher percentage of normal. Of the 145 participants who reported higher percent- age of normal for current symptoms (some participants did not answer this question), difference in percentage ratings ranged from $2 \%$ to $75 \%(\mathrm{M}=16.09, \mathrm{SD}=13.52)$.

\section{Side effects of DDS}

There are four common side effects of DDS, which need to be monitored to minimize reactions and "do no H.A.R.M." (ie, Herxheimer reactions, Anemia, Rashes, Methemoglobinemia). Herxheimer reactions represent inflammatory cytokine release (ie, tumor necrosis factor-alpha, interleukin-6 [IL-6], and IL-8) associated with bacterial killing. ${ }^{17,18}$ Anemia is secondary to the drugs' effect on folic acid metabolism, but could potentially be due to hemolytic anemia if there was glucose-6-phosphate dehydrogenase ${ }^{19}$ deficiency (which was ruled out in our patients). Rashes may be due to sulfa sensitivity (although many patients allergic to sulfamethoxazole/trimethoprim tolerate DDS), and methemoglobinemia ${ }^{20,21}$ is due to increased oxidative stress affecting the ability of hemoglobin to efficiently carry oxygen. Elevated methemoglobin levels can result in increased fatigue, headaches, blue hands, and lips as well as shortness of breath. About $66.70 \%$ of participants experienced Herxheimer reactions, $48.30 \%$ anemia, $7 \%$ rashes (which were mild), and $18.4 \%$ elevated methemoglobin levels with $3.5 \%$ experiencing blue hands, $3 \%$ blue lips, and $21 \%$ shortness of breath. Shortness of breath may have also been due to active and inadequately treated babesiosis, which can cause cough/and shortness of breath with respiratory distress. Side effects resolved quickly once stopping the drug and using higher doses of folic acid to reverse anemia, and glutathione with $\mathrm{N}$-acetyl-cysteine to lower elevated methemoglobin levels, ${ }^{22}$ based on the published scientific literature and the first author's clinical experience. Methylene blue can also lower methemoglobin levels. ${ }^{23}$ Minor side effects of DDS included temporary elevations in bilirubin, ${ }^{24}$ especially in those with Gilbert's syndrome. ${ }^{25}$

No patients suffered any long-term effects or developed Clostridium difficile during the months of DDS CT. All patients were instructed to take a minimum of three different probiotics with a total of over 100 billion live organisms/day, which contained mixtures of prebiotics (lecithin and oleic acid), lactobacilli (L. rhamnosis, L. acidophilus, L. paracasei), bifidobacterium (B. lactis, strains BL-04 and Bi-07), and Saccharomyces boulardii. It has been published in the scientific literature that these strains significantly decrease the incidence of antibiotic-associated diarrhea and support a healthy intestinal environment and immune health, although only $S$. boulardii has been shown to be effective for the prevention of $C$. difficile diarrhea. ${ }^{26-29}$ 


\section{Lyme disease testing}

Our study showed that the most common IgM and IgG Borrelia-specific bands were 23, 31, 34, 39, 83/93 kDa for patients during their treatment in our medical facility, which occasionally spanned years (Figures 1 and 2). A chart review revealed that these bands changed and/or expanded over time.

Indeterminate WB bands (weak positives) were not included in our study to eliminate false positives and increase sensitivity. Most patients studied did however have new indeterminate Borrelia-specific WB bands (23, 31, 34, 39, $83 / 93 \mathrm{kDa}$ ) appear and change over time during their illness. Figure 3 compares the number of individuals with EM rashes, positive CDC criteria WBs (IgM and IgG), and positive Lyme testing by IFA, ELISA, C6 ELISA, and ELISpot (LTT). Only a small number of patients were tested using LTT, which were done by other medical providers prior to enrolling in the study. Positive CDC WBs were defined as at least $2 / 3$ reactive $\operatorname{IgM}$ WB bands $(23,39,41 \mathrm{kDa})$ and a positive CDC IgG WB was defined as having at least $5 / 10$ IgG WB bands (18, 23 [OspC], 28, 30, 39 [BmpA], 41 [Fla], $45,58,66$, and 83/93 kDa; Figure 3).
Repeat WB testing during treatment showed that the 31 $\mathrm{kDa}$ band was positive on the IgM WB $46.2 \%$ of the time (Figure 1), and positive on the IgG WB $28.4 \%$ of the time (Figure 2). For the IgM WB, the $34 \mathrm{kDa}$ band appeared 21.5\% of the time and was positive on the IgG WB $11.7 \%$ of the time. Table 2 shows the frequencies of negative ELISA and C6 ELISA with the presence of bands 31 and $34 \mathrm{kDa}$ and negative/positive CDC IgG and IgM WBs (Table 2).

\section{Co-infections}

Many Lyme patients in our study struggled with other tick-borne illnesses. For the current work, we included information on the following tick transmissible infections as well as other infectious agents that participants may have been exposed to during their lifetime (unrelated to tick transmission). These were collected directly from the patient charts using indirect testing, that is, antibody titers (which indicate prior exposure, but not necessarily active infection) and direct testing, that is, PCR, fluorescent in situ hybridization (FISH) (which are indicative of active infection): Anaplasma, $(\mathrm{N}=27$, 13.5\%), Babesia (Babesia microti and Babesia duncani

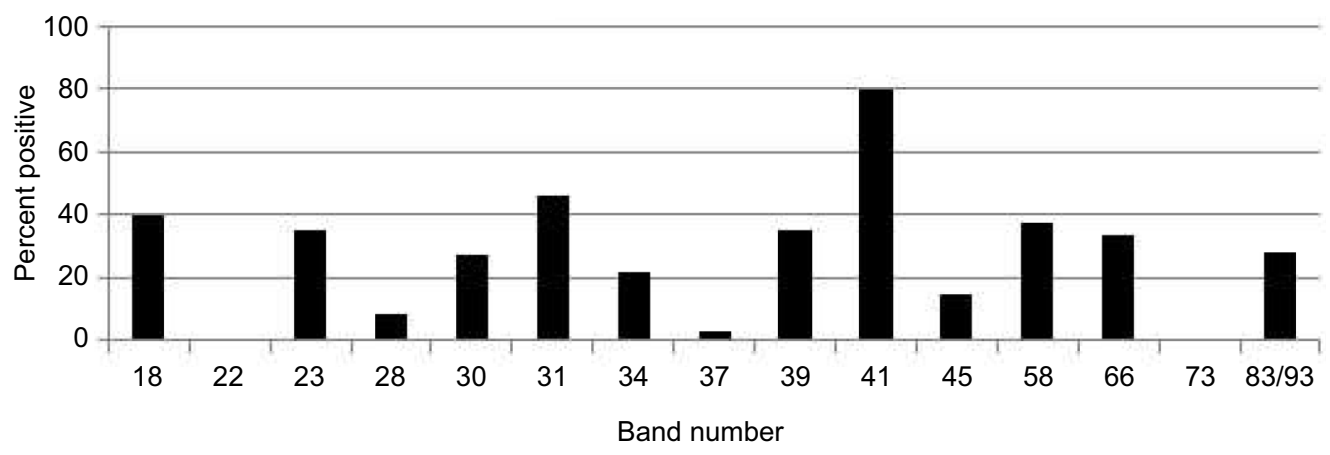

Figure I Percentage of 200 patients with IgM Western blot band(s) over the course of treatment.

Notes: Percentage of positive IgM Western blot bands over the course of treatment. A high percent of Borrelia-specific bands (23, 3I, 34, 39, 83/93 kDa) are present on the IgM Western blot in 200 patients.

Abbreviation: IgM, immunoglobulin $M$.

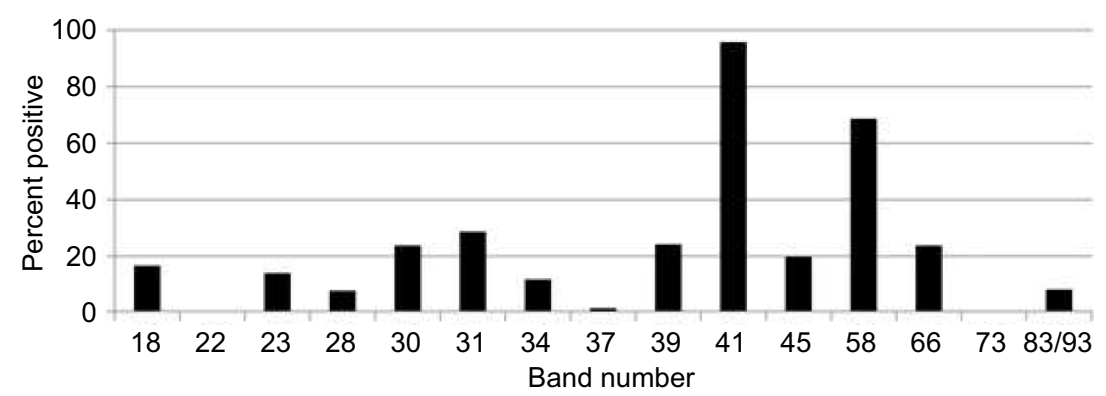

Figure 2 Percentage of 200 patients with lgG Western blot band(s) over the course of treatment.

Notes: Percentage of positive lgG Western blot bands over the course of treatment among 200 individuals. A significant percentage of individuals had the presence of the $30,3 \mathrm{I}$, and $34 \mathrm{kDa}$ bands on an IgG Western blot.

Abbreviation: IgG, immunoglobulin G. 


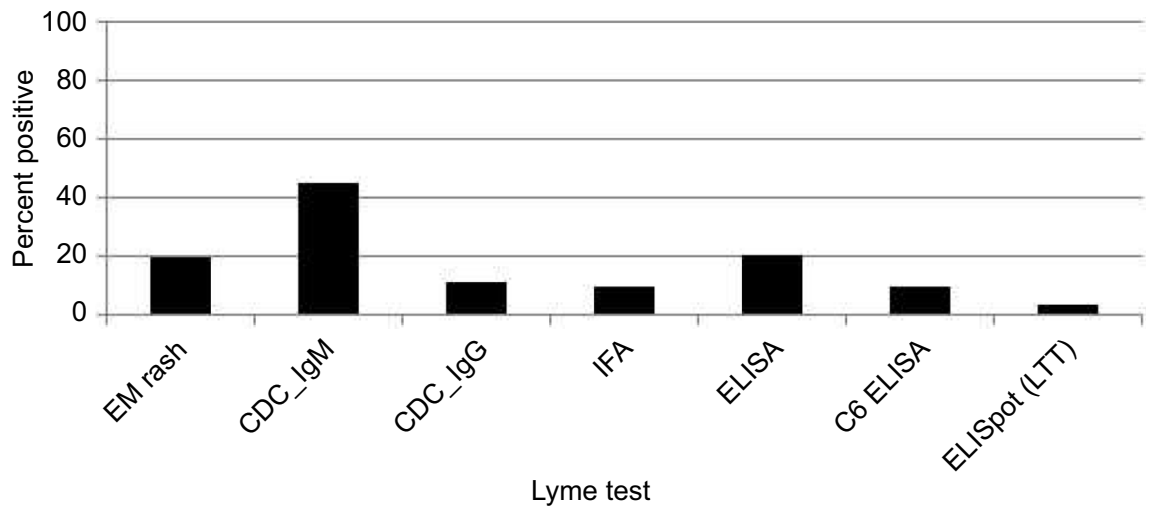

Figure 3 Percentage of patients with EM rashes and positive Lyme testing.

Notes: Percentage of patients with EM rashes and positive Lyme testing. A low percentage of positive EM rashes with a high percentage of CDC IgM Western blots were found in our 200 patients.

Abbreviations: CDC, Centers for Disease Control and Prevention; EM, erythema migrans; IFA, immunofluorescent antibody; IgM, immunoglobulin M; LTT, lymphocyte transformation test.

Table 2 Frequency and percentage of positive CDC IgG and IgM Western blots with positive bands $3 \mathrm{I}$ and $34 \mathrm{kDa}$ and a negative ELISA or negative C6 ELISA

\begin{tabular}{|l|l|l|l|}
\hline \multicolumn{2}{|c|}{} & \multicolumn{2}{|l|}{ Negative tests } \\
\cline { 2 - 4 } \multicolumn{2}{|c|}{} & ELISA (N=3 I) & C6 ELISA (N=49) \\
\hline \multirow{3}{*}{$\begin{array}{l}\text { IgG Western } \\
\text { blot }\end{array}$} & Band 3I (+) & $4(12.9 \%)$ & $16(32.7 \%)$ \\
\cline { 2 - 4 } & Band 34 (+) & $4(12.9 \%)$ & $8(16.3 \%)$ \\
\cline { 2 - 4 } & CDC (+) & $1(3.2 \%)$ & $7(14.3 \%)$ \\
\hline \multirow{3}{*}{$\begin{array}{l}\text { IgM Western } \\
\text { blot }\end{array}$} & Band 3I (+) & $12(38.7 \%)$ & $19(38.8 \%)$ \\
\cline { 2 - 4 } & Band 34 (+) & $8(25.8 \%)$ & $10(20.4 \%)$ \\
\cline { 2 - 4 } & CDC (+) & $7(22.6 \%)$ & $23(46.9 \%)$ \\
\hline
\end{tabular}

Notes: A significant percentage of positive Osp A (38\%) and Osp B (25\%) bands were found on CDC negative IgM Western blots (with negative ELISA or C6 ELISA). A significant percentage of positive Osp A (25\%) and Osp B (15\%) bands were also found on CDC negative lgG Western blots (with a negative ELISA, C6 ELISA). Abbreviation: CDC, Centers for Disease Control and Prevention.

$[\mathrm{N}=104,52 \%]$ ), Bartonella (B. henselae and B. quintana [N=93, positive by titer, PCR, FISH, and/or VEGF, 46.5\%]), Brucella $(\mathrm{N}=20,10 \%)$, Chlamydia pneumoniae $(\mathrm{N}=102$, $51 \%)$, cytomegalovirus ( $\mathrm{N}=74,37 \%)$, Coxsackie, $(\mathrm{N}=15$, 7.5\%) Epstein-Barr virus (EBV) (N=160, 80\%), Ehrlichia $(\mathrm{N}=29,14.5 \%)$, Helicobacter pylori $(\mathrm{N}=15,7.5 \%)$, Herpes simplex virus (HSV1) $(\mathrm{N}=46,23 \%)$, HSV2 ( $\mathrm{N}=23,11.5 \%)$, human herpes virus 6 (HHV6) ( $\mathrm{N}=162,81 \%)$, Mycoplasma (M. pneumonia, M. fermentans, and M. penetrans $[\mathrm{N}=164$, $82 \%]$ ), Parvovirus (N=23, 11.5\%), Q-Fever (Coxiella burnetti $[\mathrm{N}=17,8.5 \%]$ ), RMSF (Rickettsia $[\mathrm{N}=20,10 \%]$ ), Toxoplasmosis $(\mathrm{N}=23,11.5 \%)$, tularemia $(\mathrm{N}=33,16.5 \%)$, typhus $(\mathrm{N}=10,5 \%)$, and West Nile Virus $(\mathrm{N}=13,6.5 \%)$. Participants tested positive for exposure to between 0 and 16 infections $(M=5.87, S D=2.29)$. In addition to their Lyme disease, of 200 participants, $0.5 \%$ had no evidence of other infections/coinfections, $26 \%$ had evidence of prior exposure to 2-4 infections/coinfections, $64 \%$ had evidence of prior exposure to 5-8 infections/coinfections, $8 \%$ had evidence of prior exposure to 9-12 infections/coinfections, and $1.5 \%$ had evidence of exposure to $>12$ infections/co-infections. Figure 4 illustrates the high frequency of tick transmissible infections and other infectious agents in our 200 patients, most notably for Babesia, Bartonella, C. pneumoniae, EBV, HHV6, and mycoplasma.

\section{New findings: co-infections are the rule and several tick species have spread}

New findings include evidence of more than one co-infection in the majority of the 200 patients (Figure 4) and serological evidence of not only $B$. microti $(\mathrm{N}=51,25.5 \%)$ but also $B$. duncani $(\mathrm{N}=56,28 \%)$. Some patients had evidence of antibody titers for both the species ( $\mathrm{N}=20,10 \%$; Figure 5). Out of 32 patients who were seronegative for B. microti and/or B. duncani, $37.5 \%$ were positive by direct testing (PCR, FISH). One was PCR positive (3\%) and 11 were FISH positive (34.5\%), illustrating the need for a broad screening approach to detect babesiosis.

B. duncani babesiosis has been reported to exist primarily in the Western United States, although the spread of WA-1 babesiosis has occasionally been found in diverse geographic areas of the United States. ${ }^{30}$ Based on positive antibody titers for B. duncani from patients living in the Northeast, Upper Midwest, and Southwestern United States (Table 3; Figure 6), which were reported from several national and specialty laboratories (Quest Diagnostics, LabCorp, BioReference Laboratory, Medical Diagnostics Laboratory, and IgeneX), this finding implies that there has been a spread of $B$. duncani across the United States, and especially in the Northeastern 


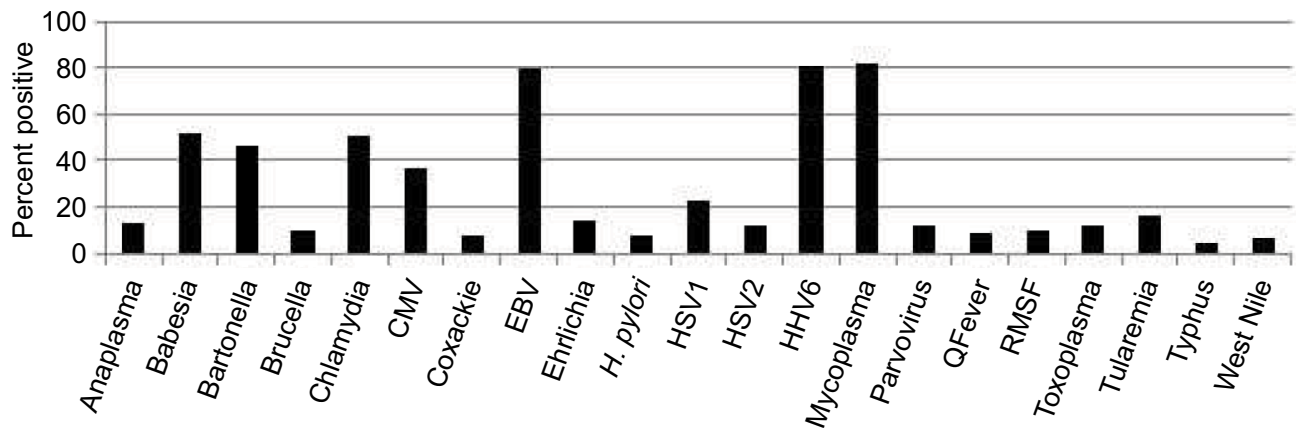

Co-infection frequency amoung 200 Lyme disease patients

Figure 4 Percent positive testing for coinfections over the course of treatment among 200 Lyme disease patients. These results demonstrate a high percentage of coinfections.

Abbreviations: CMV, cytomegalovirus; EBV, Epstein-Barr virus; H. pylori, Helicobacter pylori; HHV6, human herpes virus 6; HSVI, Herpes simplex virus I; HSV2, Herpes simplex virus 2; RMSF, Rocky Mountain spotted fever.

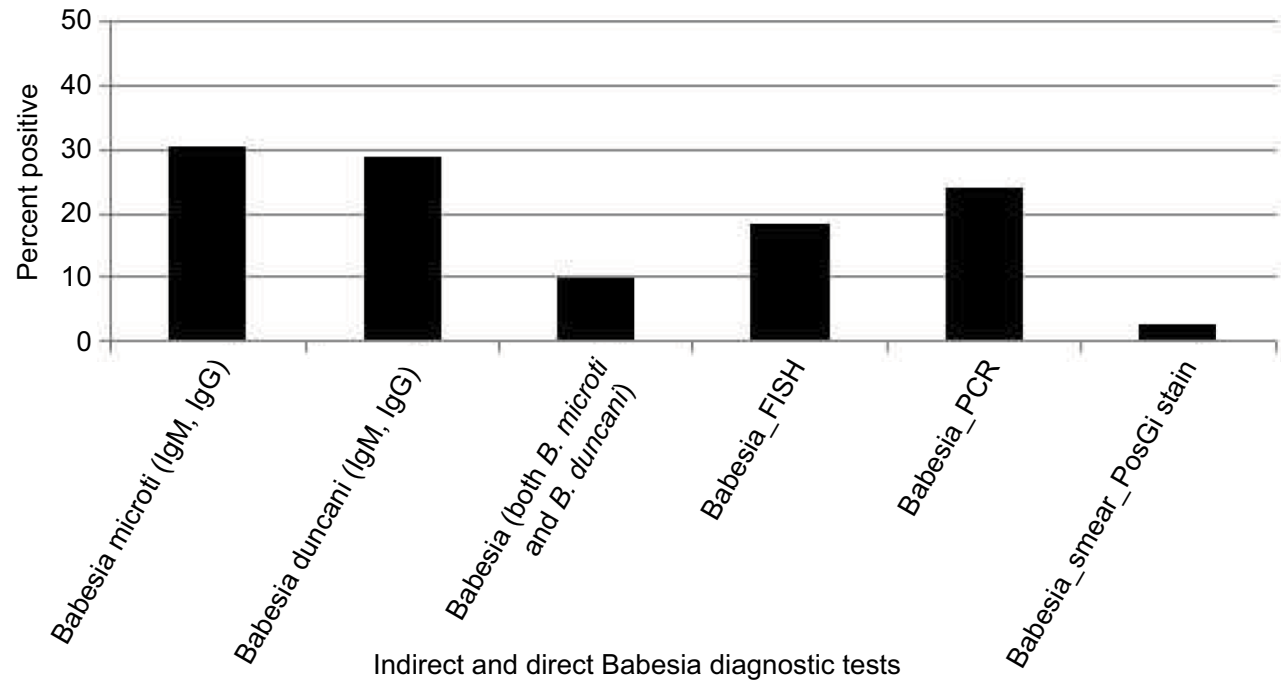

Figure 5 Indirect and direct Babesia diagnostic testing among 200 patients with Lyme disease.

Note: Results demonstrate the percentage of positive B. microti and B. duncani titers, and percentage of positive direct testing (PCR, FISH, blood smear/positive Giemsa stain). Abbreviations: FISH, fluorescent in situ hybridization; PosGi, positive Giemsa.

Table 3 Babesia subtypes by demographic region in 200 Lyme disease patients

\begin{tabular}{|l|l|l|l|}
\hline & N & Babesia duncani & Babesia microti \\
\hline East Coast (North) & I55 & 43 & 44 \\
\hline East Coast (South) & 20 & 6 & 3 \\
\hline Midwest & 16 & 6 & 3 \\
\hline West Coast & I & 0 & 0 \\
\hline Other (Hawaii) & I & I & I \\
\hline International & 7 & 0 & 0 \\
\hline
\end{tabular}

Notes: Positive antibody testing for B. microti and B. duncani among 200 patients with Lyme disease living in diverse geographic areas of the United States.

United States. Figure 6 illustrates antibody-positive $B$. duncani cases by home state in 200 patients.

\section{Discussion}

The significant increase in Lyme disease cases during the past 20 years $^{12}$ highlights the imperative of performing and patients receiving an accurate diagnostic evaluation. To diagnose Lyme disease, physicians often rely on clinical presentation (the appearance of an EM rash) and/or two-tiered testing when a patient presents with a chronic fatiguing, musculoskeletal illness with cognitive difficulties. Schutzer et al recently reported limitations of serodiagnostic testing which have a number of shortcomings, including the inability to distinguish active infection, past infection, or reinfection. ${ }^{31}$

In this retrospective chart review/observational study of 200 patients with tick-borne disorders, only $19.5 \%$ had evidence of an EM rash. Although prior studies indicate that EM occurs in $70 \%-80 \%$ of cases, ${ }^{32}$ multiple variables including rash appearance and gender may influence accurate reporting ${ }^{33,34}$ and an updated study on the diagnosis and treatment of Lyme disease found it to be present in only a minority of cases (as low as 9\%). ${ }^{35}$ Some patients might not 


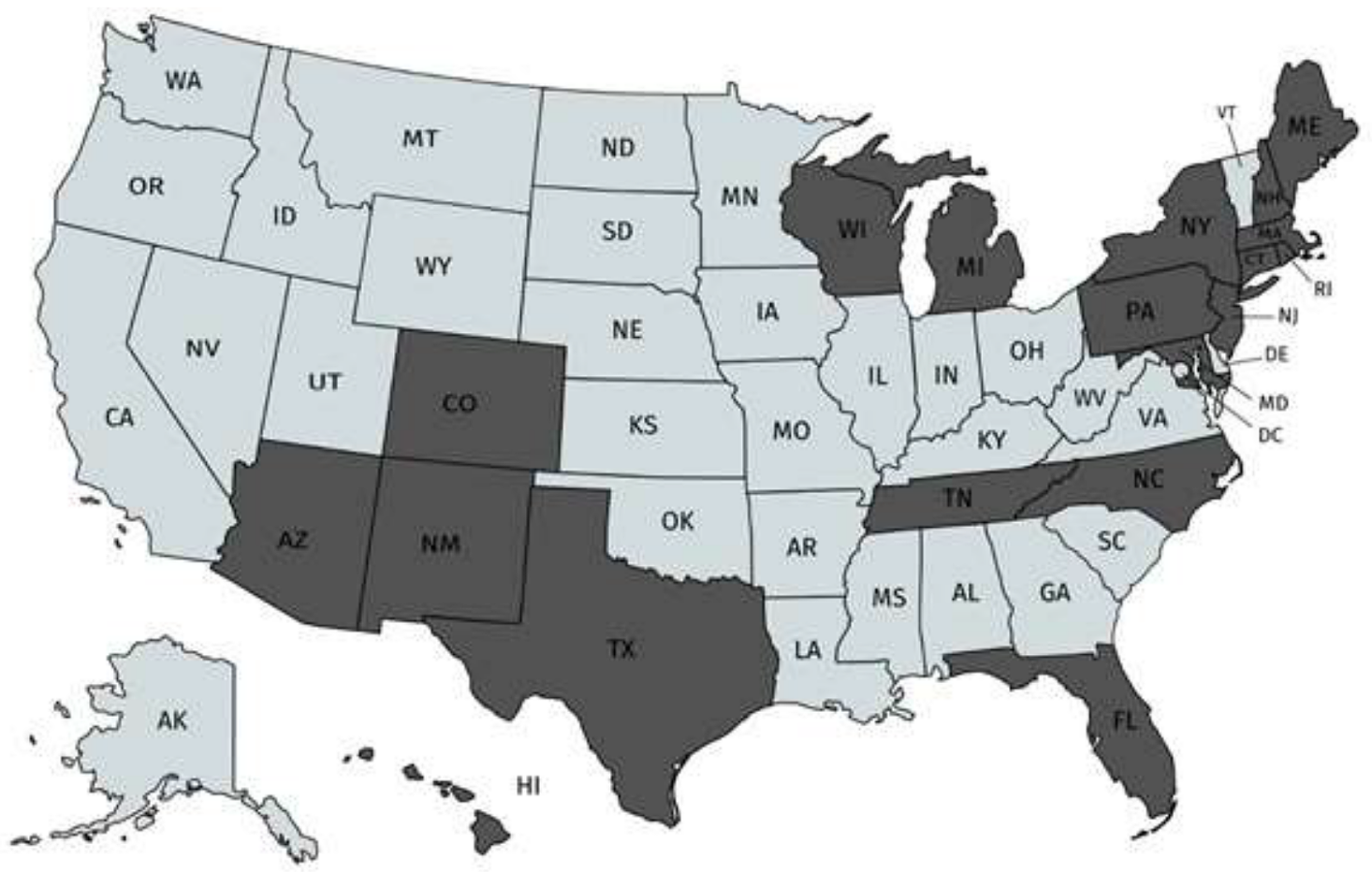

Figure 6 Antibody-positive Babesia duncani cases by home state in 200 patients.

Notes: US regional frequency of positive testing for $B$. duncani. Dark colored states indicate home states of patients with positive $B$. duncani testing.

notice an EM rash. Our patient population also had a low incidence of positive IFAs (10\%), ELISAs (20.5\%), and C6 ELISAs (10\%). These are first-line tests that some clinicians use to determine if a WB is needed, regardless of CDC recommendations that surveillance case definitions should not be relied upon to make a clinical diagnosis. ${ }^{36}$ Despite a low incidence of positive IFAs, ELISAs, and C6 ELISAs, we found that $11.5 \%$ had CDC-positive IgG WBs and $45 \%$ of patients had CDC-positive IgM WBs. Some clinicians choose to ignore the significance of a positive IgM WB in a patient with chronic Lyme symptoms, attributing it to a false-positive test, although the medical literature has shown that positive IgM blots can be found in late Lyme. ${ }^{37}$ That was the case in our patient population who responded positively to DDS CT. A sizeable number of these patients with a chronic fatiguing, musculoskeletal, neurocognitive illness with a negative ELISA and/or C6 ELISA also had a significant percentage of Borrelia-specific bands $(23,31,34,39,83 / 93 \mathrm{kDa})$ on their $\mathrm{WB}$, pointing to probable exposure with a Borrelia species (B. sensu lato). A recent 2017 study by Embers et al using non-human primates showed that variable manifestations of Lyme disease can exist with diverse seroreactivity. After antibiotic treatment for disseminated infection, posttreatment persistence with intact, metabolically-active $B$. burgdorferi was found and may not be reflected by maintenance of specific antibody production by the host. ${ }^{38}$

Diagnostic testing for Lyme is known to lack adequate sensitivity, specificity, and reliability, ${ }^{39-41}$ and false seronegativity has been extensively reported in the peer review medical literature. ${ }^{42-52}$ Many B. sensu lato species and relapsing fever borrelia (ie, Borrelia miyamotoi), as well as some species of Babesia, Bartonella, and Mycoplasma may also not be found on commonly used antibody testing. ${ }^{53}$ For example, patients were oftentimes positive for one species of Babesia by antibody testing, but negative for another, or only were positive on PCR and/or FISH testing. In 32 of our patients who were antibody negative for either $B$. microti and/or $B$. duncani, $37 \%$ were positive by direct testing (one was PCR positive and eleven were FISH positive). One patient with Chronic Variable Immune Deficiency (CVID) with negative Lyme antibody testing (IFA, C6 ELISA), but with Borreliaspecific bands on a $\mathrm{WB}$, was positive for antibodies against the relapsing fever borrelia, B. miyamotoi (GlpQ+). This presents a clinical dilemma for both healthcare providers and patients who are searching for answers for their chronic illness.

A recently validated symptom questionnaire for Lyme disease, the Horowitz Multiple Systemic Infectious Disease 
Syndrome Questionnaire (HMQ) may be useful to evaluate the pretest probability of a tick-borne disorder. ${ }^{13}$ The HMQ was shown to demonstrate satisfactory psychometric properties, including construct validity, divergent validity, and predictive validity. Scores for the HMQ in the "likely" or "highly likely" categories should lead providers to do a broad panel of tick-borne testing. Testing should include not only an ELISA, which has limited sensitivity ${ }^{41}$ but also a C6 ELISA ${ }^{54}$ and IgM/IgG WBs, focusing on the presence of Borrelia-specific bands ${ }^{15}$ to capture the varied species of Borrelia. B. sensu lato $^{55}$ and relapsing fever Borrelia ${ }^{56}$ which are now known to also cause chronic illness.

The presence of Borrelia-specific bands helped to confirm the clinical diagnosis of Lyme disease after other diseases had been ruled out. ${ }^{15,57}$ These bands include the $23 \mathrm{kDa}$, Osp C (21-24 kDa), $31 \mathrm{kDa}$ (OspA), $34 \mathrm{kDa}(\mathrm{OspB}), 39 \mathrm{kDa}$ and $83 / 93 \mathrm{kDa}$ bands. The $41 \mathrm{kDa}$ and Borrelia proteins of the $60-75 \mathrm{kDa}$ range (especially $66 \mathrm{kDa}$ ) are non-specific and can cross-react with non-borrelial antigens. ${ }^{58,59} \mathrm{New}$ Borrelia-specific bands appearing over time in individuals with ongoing symptoms (especially migratory pain) was suggestive of an active infection in the proper clinical setting, and several patients were also PCR-positive despite seemingly "adequate" antibiotic therapy for months or years prior to DDS therapy ( $\mathrm{N}=29,14.5 \%)$. Some patients (16.8\%) also had evidence of exposure to Borrelia hermsii, a relapsing fever borrelia, although false seropositivity due to an infection with Borrelia burgdorferi could not be ruled out. ${ }^{59}$ $B$. hermsii and B. burgdorferi infections produce antibodies that also cross-react with $B$. miyamotoi antigens, making the serodiagnosis difficult. ${ }^{60}$

A 2018 publication by Strobino et a $^{61}$ indicated that for convalescent EM, combinations of the C6 ELISA with a second-tier ELISA or line blot may provide useful alternatives to WB-based testing algorithms, but this needs to be confirmed in larger clinical studies. For those without an EM rash (and not meeting the definition of PTLDS), the two-tiered testing strategy for diagnosing $B$. burgdorferi misses a large proportion of cases, ${ }^{62}$ and this approach cannot diagnose new species of Borrelia, including B. miyamotoi and B. burgdorferi sensu lato, which are also known to cause chronic illness. ${ }^{63,64}$ These infections are spreading across the United States and Europe. Recently, B. miyamotoi was found to have a higher prevalence of infection in Ixodes pacificus, western blacklegged ticks compared to its eastern counterpart, and other tick species not currently recognized as competent vectors (Ambylomma americanum and Arum maculatum) were also observed to have B. miyamotoi infections..$^{65}$ Although there can be a great deal of heterogeneity in the protein patterns among $B$. sensu lato species, proteins OspA $(31 \mathrm{kDa})$ and OspB (34 kDa) have been reported (plus OspA at $33 \mathrm{kDa}),{ }^{66}$ as well as $\mathrm{OspC}(23 \mathrm{kDa}), 39 \mathrm{kDa}$, and $83 \mathrm{kDa} \cdot{ }^{67}$ These are the same proteins we frequently found in Lyme-MSIDS patients in our study (Figures 1 and 2). Non-specific antibody can be present in sera and bind to a protein that co-migrates to the same position on a WB as OspA. ${ }^{68}$ Although this protein can be found in certain viral infections like EBV, Lyme immunoblots with recombinant OspA may be a solution to improve testing specificity. ${ }^{69}$

Osp A is not considered as a major antigen produced in mammals (early inhibition of OspA and OspB is needed for vertebrate infection, since B. burgdorferi mutants that express OspA and Osp B are rapidly killed by host immune responses), but the protein appears to be produced in some patients with chronic Lyme symptoms. ${ }^{70}$ These proteins have been linked to more severe arthritic and neurological diseases (encephalopathy, myelopathy, and peripheral neuropathy) with autoimmune manifestations. ${ }^{71-73}$ Repeat IgM and IgG WB testing during treatment showed that the $31 \mathrm{kDa}$ band was positive $46.2 \%$ and $28.4 \%$ of the time, respectively. For the IgM WB, the $34 \mathrm{kDa}$ band appeared $21.5 \%$ of the time and was positive on the IgG WB $11.7 \%$ of the time. Unfortunately, not all laboratories report the full spectrum of bands since OspA and OspB are not part of the CDC surveillance criteria for either a positive $\operatorname{IgM}$ or $\operatorname{IgG}$ WB. These bands can be specific for exposure to multiple Borrelia species assuming there has been no recent viral infection or Lyme vaccination. The serological findings of patients in our study showed a considerable number with negative ELISA and C6 ELISA test results (Figure 3), but were positive on OspA (31 kDa) and OspB (34 kDa) bands on a WB, as shown in Figures 1 and 2 . We therefore suggest that these bands be reported and followed in all WB specimen results to inform the healthcare provider as to the probability of exposure and active infection in chronic disease. This is especially important based on the spread of new Borrelia species in the United States and Europe, where the ability to cause EM differs between B. burgdorferi sensu lato isolates. ${ }^{74}$

Most of our 200 patients $(\mathrm{N}=165)$ statistically improved their eight major Lyme symptoms on DDS CT $(P<0.001)$ despite failing or relapsing on prior therapy. Patients served as their own controls. Resistant fatigue, myalgias, joint and nerve pain, headaches, sleep and cognitive disorders all improved, as well as malarial-like symptoms (day and night sweats, chills, flushing). The majority also had evidence of exposure to multiple infections/coinfections. These included 
Anaplasma (13.5\%), Ehrlichia (14.5\%), Babesia (52\%), Bartonella (46.5\%), Mycoplasma (82\%), RMSF (10\%), Q-Fever (8.5\%), typhus (5\%), tularemia (16.5\%), Brucella (10\%), C. pneumoniae $(\mathrm{N}=102,51 \%)$, and H. pylori $(7.5 \%)$. Viral infections included HSV1 (23\%), HSV2 (11.5\%), HHV6 (81\%), parvovirus $(11.5 \%)$, and West Nile virus (6.5\%). Parasites found were toxoplasmosis, as well as B. microti and B. duncani. Inherent limitations of our testing strategies (which were done primarily using antibody and PCR technology) interfered however with our ability to detect multiple species of coinfections that could be causing symptoms yet would not be found on commonly used testing. For example, some patients with Babesia were seronegative and only positive with RNA testing, patients were not routinely tested for all species of Mycoplasma (including $M$. fermentans and $M$. penetrans), and although a considerable percentage of our patients tested positive for Bartonella henselae, there are at least 38 different species and subspecies of Bartonella (and proposed Candidatus species), some of which have been associated with human disease. ${ }^{75}$ We did not have access in our NY clinic to specialty laboratories that are able to evaluate a broader range of bartonella infections unless done in other states. As per the Report of the Other Tick-Borne Diseases and Coinfections Subcommittee to the Tick-Borne Disease Working Group posted on the Health and Human Services (HHS) website on May 4, 2018, ${ }^{76}$ Bartonella species can also be extremely difficult to diagnose by clinicians, as there is evidence that they hide in the intracellular compartment. Without broad-based sensitive serology, testing can be negative. The sensitivity of confirming a diagnosis by direct detection also continues to be an area that needs improvement in other tick-borne diseases and co-infections. Therefore, the true number of individuals with Babesia and Bartonella infections and less frequently diagnosed tick-borne infections/ coinfections like RMSF, Q-fever, tularemia, and Brucella needs to be confirmed in future studies on PTLDS/chronic Lyme disease. Low positive titers for these infections could be the result of cross reactivity with other rickettsial and intracellular infections, although some individuals reactivated their infections over time with fourfold increases in titers, or positive agglutination testing that is, Brucella. We found a $10 \%$ incidence of positive titers to RMSF $(\mathrm{N}=20)$, and as per the HHS report, "about $10 \%$ of people in the United States (and worldwide) have pre-existing spotted fever group rickettsiae (SFGR)-specific antibodies. Thus, a healthcare provider might treat a patient with a positive reaction to a Rocky Mountain spotted fever (RMSF) serological test for RMSF when they should be looking at another cause of the patients' disease... This illustrates the power and limitations of serology and the need for paired tests, which cannot definitively confirm or rule out the presence of infection."76

The considerable number of $B$. duncani antibody tests $(\mathrm{N}=175,28 \%)$ discovered in residents living in the Northeast was unexpected. False-positive serology to B. duncani is possible, which can be associated with acute EBV infection, but all the patients in our study with EBV had prior exposure, without evidence of an active infection (by PCR). Only one patient was EBV PCR positive in 2003, who was also HHV-6 PCR positive and $B$. microti antibody negative at that time, whose $B$. duncani/WA-1 titer turned positive 10 years later in 2013. At that point in time, she was EBV and HHV-6 PCR negative with decreasing EBV capsid IgG antibody titers. It is therefore not likely that $B$. duncani/WA-1 antibody reactivity in any of our patients was attributable to polyclonal B-cell activation from viral infections. Similarly, although travel to the West/Pacific Coast cannot be ruled out as a potential cause of exposure of $B$. duncani, two recent publications in 2018 reported range expansion of human babesiosis in the northeastern United States, ${ }^{77}$ as well as widespread distribution of B. duncani across Canada. ${ }^{78} \mathrm{~A}$ considerable proportion of those cases $(67.7 \%)$ reported by Scott et al in 2018 were found in Quebec, New Brunswick, Newfoundland, and Nova Scotia, on the eastern Canadian seaboard close to Maine. Seven percent of the 200 patients in our study lived in Maine and tested positive for $B$. duncani. This implies spread of the babesia parasite by migratory songbirds, ${ }^{79,80}$ although it is also possible that the original discoverers of Babesia WA-1 (later termed $B$. duncani) failed to recognize its presence in other geographic areas. Other tick-borne infections are known however to be spread through migratory birds ${ }^{81-83}$ such as $B$. sensu lato spp. in northwestern California, ${ }^{84,85}$ and rickettsia fever was spotted throughout Europe. ${ }^{82}$

New ticks and tick-borne infections can appear in areas where they were not previously recognized. That was the case for the Asian longhorn tick (Haemaphysalis longicornis), foreign to the United States, which was recently found in New Jersey, ${ }^{86}$ Virginia, West Virginia, Arkansas, and North Carolina ${ }^{87}$ as well as Connecticut and New York. ${ }^{88}$ This tick is known to be a competent vector for a phlebovirus causing severe fever with thrombocytopenia syndrome, as well as being able to transmit the alpha gal allergy in other parts of the world. ${ }^{89}$ Although these infections and tick-borne disorders have not yet been associated with $H$. longicornis in the United States (the primary cause of alpha gal allergy in the United States is the lone star tick, A. americanum),${ }^{90}$ enhanced screening and prevention practices are necessary. One of 
the patients we evaluated from the Southern United States had a borderline positive IgE antibody against galactose-a-1, 3-galactose (alpha-gal) with symptoms consistent with alpha gal meat allergy (delayed urticarial, GI disorder symptoms, and/or airway angioedema minutes to hours post ingestion of meat or gelatin capsules containing BSA).

Tick species are expanding in areas not previously seen (lone star ticks have expanded from the Southeastern States to Long Island, NY, USA leading to increasing cases of alpha gal allergy), and in 2018 seroprevalence to other flaviviruses like the Powassan virus was shown to be increasing in Lyme endemic areas across the United States. ${ }^{91}$ Thirty three viruses, including 24 putative novel viral species, were also recently discovered in Ixodes scapularis, A. americanum, and Dermacentor variabilis ticks collected in New York, Connecticut, and Virginia in 2018. ${ }^{92}$ Although the role of these viruses has not yet been determined, ticks containing multiple tick-borne infections including bacteria, viruses, and parasites (Babesia spp.) are increasing and require ongoing surveillance, especially since multiple tick-borne infections like Babesia also pose a risk for the blood supply ${ }^{93}$ along with the possibility of maternal-fetal transmission. ${ }^{94}$

Increasing co-infection of blacklegged ticks with Babesia spp. and B. burgdorferi is expected in the United States as reported by researchers at the Cary Institute of Ecosystems Studies in New York. ${ }^{95}$ Based on our study, B. duncani may have spread to areas not previously recognized, just as exposure to the Powassan virus has been shown to be increasing. Since "there have only been 13 B. duncani (WA-1 babesiosis) cases for which incontrovertible evidence of the disease etiology (direct detection of the agent by blood smear or PCR; hamster inoculation; in vitro culture) has been reported and accepted by the Centers for Disease Control and Prevention...," 76 our finding needs to be confirmed in larger clinical studies, using well-validated samples. Many patients who were $B$. microti negative and $B$. duncani positive with malarial like symptoms (fevers, sweats, chills, flushing, "air hunger" with an unexplained cough) did improve with Babesia therapy (atovaquone, atovaquone/proguanil, azithromycin, and clindamycin). B. duncani testing should therefore be considered in any patient with an unexplained fatiguing, febrile illness and suggestive lab testing (anemia, thrombocytopenia, and transaminitis) living in the northeastern United States, who becomes ill after a tick bite or blood transfusion. Increased morbidity and mortality from babesiosis can be seen in the very young, ${ }^{96}$ elderly, immunosuppressed, ${ }^{97}$ (and asplenic) as well as in those with associated comorbidities. ${ }^{98}$

\section{Other testing to consider}

A CBC and CMP to look for the presence of leukopenia, thrombocytopenia, and transaminitis should be performed in patients with suspected tick-borne infections, as these can occur with Ehrlichia, Anaplasma, rickettsial infections, ${ }^{99}$ as well as Borrelia species including B. miyamotoi. ${ }^{100}$ Other tick-borne infections like babesiosis should also be considered in severely ill patients ${ }^{101}$ since it is frequently transmitted at the same time as borreliosis and can cause similar hematological abnormalities (leucopenia, thrombocytopenia, and transaminitis) as well as hemolytic anemia (Babesia divergens increases the risk). ${ }^{102}$ Recent findings in the mouse model suggest that $B$. burgdorferi coinfection attenuates parasite growth while B. microti presence exacerbates Lyme disease-like symptoms. ${ }^{103}$ Any patient who complains of unexplained fevers, day and night sweats, chills, flushing, an unexplained cough, and shortness of breath (air hunger), which are questions number 1 and number 22 (Section 1 of the HMQ), may have a concomitant infection with babesiosis. ${ }^{102,104,105}$ Malarial-like symptoms can however be present with or without associated laboratory abnormalities, including leucopenia, thrombocytopenia, transaminitis, and hemolytic anemia, and patients who are co-infected and/or with low levels of parasitemia may not present with the classical symptoms of babesiosis. ${ }^{53}$ Hematological abnormalities including transaminitis usually resolved with anti-infective therapy unless there were other underlying etiologies (one patient was found to have alpha-1-antitrypsin deficiency, and another was positive for hemochromatosis). A Babesia panel approach with a Giemsa stain, Babesia titers (IFA) for multiple species of Babesia ( $B$. microti, B. duncani [WA-1], B. divergens, and Babesia sp. EU1), with PCR ${ }^{106}$ and FISH testing ${ }^{107}$ may help to establish the diagnosis in the United States and Europe, ${ }^{108}$ while ruling out other causes of these symptoms. The Babesia PCR screen used in our study detected Babesia-specific DNA for $B$. microti and/or B. duncani. Several of our patients were FISH (RNA) positive (34.5\%) while being antibody/PCR negative, highlighting the importance of a broad screening approach to detect babesiosis.

Other potential tick-borne transmitted infections, including Bartonella ${ }^{109}$ and tularemia, ${ }^{110}$ should also be considered in the differential diagnosis in those experiencing an unexplained chronic fatiguing, musculoskeletal illness, as well as brucellosis, which has been found in a small percentage of individuals from the Midwest United States diagnosed with chronic fatigue syndrome (CFS). ${ }^{111}$ Approximately $46 \%$ of our patients tested positive for Bartonella species and 16.5\% 
had positive antibody titers for tularemia. One patient in our study with an unexplained autoimmune disease (Behcet's syndrome) who had failed almost 20 years of various disease modifying anti-rheumatic drug therapies initially had negative Bartonella titers, a low positive tularemia titer, and a negative VEGF, along with low positive HHV6 titers. After using DDS combination intracellular therapy, her Bartonella titer and VEGF turned positive for the first time in years, tularemia titers increased fourfold (1:320+) and HHV-6 titers similarly increased to $1: 1,280$, suggesting that this protocol unmasked occult seronegative intracellular infections. ${ }^{112}$

The discovery of chronic HHV6, Bartonella, and Mycoplasma was confirmed in other patients in our study with Lyme disease. One patient with Lyme and B. henselae (IgG 1:64+) had a positive Bartonella PCR and two positive Lyme PCRs several years apart although they had been on commonly used antibiotic therapy for both infections. Another patient with Lyme disease, Anaplasmosis, and babesiosis (positive B. microti [IgM 1:16+], B. duncani [1:256+], Babesia PCR and FISH+) had three positive HHV6 PCRs, positive repeat Babesia FISH testing (despite atovaquone and azithromycin), as well as positive PCR testing for $B$. henselae and Mycoplasma species despite several years of combination intracellular antibiotic therapy for the above infections.

Intracellular co-infections like Mycoplasma have been found in patients with CFS, who were subsequently diagnosed with B. burgdorferi. ${ }^{113}$ Most of the patients in our study showed exposure to Babesia, Bartonella, and Mycoplasma, with smaller numbers showing exposure to Anaplasma, Ehrlichia, Rocky Mountain Spotted Fever, Q-fever, tularemia, and brucella. In prior clinical studies, $\sim 70 \%$ of chronic Lyme patients showed exposure to systemic Mycoplasma species infections, and the species predominantly found in Lyme patients was $M$. fermentans. ${ }^{53} M$. fermentans has been found in ticks in Northern California, New York, and New Jersey, ${ }^{114}$ and evidence for disseminated Mycoplasma fermentans in New Jersey residents with antecedent tick attachment and subsequent musculoskeletal symptoms has been published in the scientific literature, ${ }^{114}$ although the role of Mycoplasma species and proof of vector competency of ticks still needs to be confirmed in larger clinical studies.

Once the diagnosis has been established, the advantage of using DDS in the setting of individuals exposed to Lyme and Babesia, other intracellular coinfections, with/or without associated autoimmune phenomenon, is that DDS has been shown to be effective for autoimmune illnesses like Behcets syndrome ${ }^{10}$ while also being efficacious against borrelial and malarial type parasitic infections like Babesia. ${ }^{8}$ Combining it with doxycycline and rifampin helps to broaden the intracellular coverage. These clinical findings (exposure to Borrelia, Babesia, and intracellular infections along with autoimmune phenomenon) were often present in chronically ill individuals suffering with tick-borne disease in our study. Well controlled studies are needed in the laboratory and clinical setting to establish the role of DDS CT, biofilms, and persisters in tick-borne illness.

We also did not control for a placebo effect. The three hallmarks of a placebo effect that influence treatment outcomes are the roles of conditioning, expectancy, and doctor-patient relationship. ${ }^{115}$ Patients who had come to us from other medical practices would have been exposed to these same factors, yet their symptoms did not improve or only had short lived benefit to their treatment. Placebo effects are also typically short-lived phenomenon especially in pain, ${ }^{116}$ and our patients had sustained musculoskeletal and neuropathic pain relief with DDS CT. Since more than $66 \%$ of our patients had Herxheimer reactions (and oftentimes improved afterward), a "nocebo" effect is also possible and cannot be ruled out. It is less likely however in the setting of chronic Lyme/PTLDS, since Herxheimer reactions are a well-established phenomenon secondary to antibiotics causing cytokine release.

One of the clinical challenges for healthcare providers and patients that emerged from our study is that Borrelia, Bartonella, and Mycoplasma species, as well as B. microti, were all shown to persist despite commonly prescribed courses of antibiotics or antimalarial/Babesia therapy. This has been confirmed in other scientific research studies. ${ }^{64,97,111,117-128}$ One of the patients in our study even had evidence of persistent Babesia by both DNA (PCR) and RNA (FISH) analyses despite using clindamycin and quinine, as well as atovaquone and azithromycin. Although previously reported as far back as 1999 by Horowitz, ${ }^{129}$ some of the immune and genetic etiologies responsible for persistence of the Babesia parasite were not determined until 2010 by Wormser ${ }^{130}$ as well as Lemieux et al in $2016^{131}$ when mutations in the $c y t b$ and $r p l 4$ genes of $B$. microti were discovered in patients with resistant infections. Research into more effective treatments for babesiosis are urgently needed.

Tick-borne bacterial infections including Lyme disease, bartonella species, rickettsia (Q-fever, Coxiella burnetti), tularemia, and mycoplasma species (M. fermentans) can exist as chronic infections located in the intracellular compartment, subsequently increasing inflammation. In our clinical study, the majority of patients showed exposure to M. pneumonia, ${ }^{132}$ and five patients $(2.5 \%)$ tested positive by 
PCR for M. fermentans, while two patients tested positive (1\%) by PCR for M. penetrans (not all patients were evaluated for these subspecies). One of the patients in our study was PCR positive for $M$. fermentans three times consecutively over a 15-month period. In a prior retrospective study done in 2003, persistence of Mycoplasma species was seen for up to almost 1 year with single drug intracellular therapy, ${ }^{128}$ which included the use of tetracyclines, macrolides, or quinolones. Another patient was Bartonella FISH (RNA) positive despite prolonged antibiotic therapy. Doxycycline, rifampin, and DDS CT along with Plaquenil (which alkalanizes the intracellular compartment and has an effect on round body forms) ${ }^{133,134}$ and grapefruit seed extract ${ }^{135}$ (which also addresses cyst forms/cell wall deficient forms) combined with agents that disrupt biofilms (Stevia, oregano oil) ${ }^{136}$ have the ability to affect different forms of multiple bacteria and parasites simultaneously, even if seronegativity exists. This triple intracellular antibiotic regimen produced statistical improvement in our group of patients with Lyme and associated coinfections, despite prior use of one or two drug regimens. Whether that combination is effective against the broad range of intracellular co-infections we discovered in our patients still needs to be confirmed in larger controlled studies.

When Lyme is combined with coinfections like Anaplasma, Babesia, and Bartonella, it is especially important to address factors interfering with normal immunity. Although most of our patients had comorbidities (ie, multiple coinfections, sleep disorders, nutritional deficiencies, and other abnormalities on the MSIDS map affecting inflammation), many of our patients also had evidence of immune deficiency. Thirty six of 175 patients tested had low IgG levels (20.6\%), including 14 who had CVID; 45 patients had low IgG subclass $1(\mathrm{~N}=163,27.6 \%), 30$ patients had low IgG subclass $2(\mathrm{~N}=164,18.3 \%), 51$ patients had low IgG subclass $3(\mathrm{~N}=164,31.1 \%)$, and 14 patients had low IgG subclass 4 $(\mathrm{N}=164,8.5 \%)$ with several patients having a poor response to a pneumococcal challenge $(\mathrm{N}=4,7.8 \%)$. These immune deficiencies could impact both the production of positive antibodies and associated morbidity from babesiosis, and other infections like Anaplasma. Anaplasma can have adverse effects on the immune system, and $13.5 \%$ of our patients had positive antibodies against $A$. phagocytophilum. A. phagocytophilum uses multiple evasion strategies to inhibit neutrophil antimicrobial functions. One mechanism is its ability to inhibit the fusion of the lysosomes with the cytoplasmic vacuoles while arresting or inhibiting signaling pathways. Leukopenia and impaired function of neutrophils in patients with HGA can promote susceptibility to secondary and opportunistic infections. There is some evidence of immunosuppression in patients with HGA, and small numbers of our patients showed exposure to Anaplasmosis. During infection, A. phagocytophilum also upregulates the production of chemokine IL-8 as well as pro-inflammatory cytokines, contributing to its pathophysiological effects. We see similar increases in symptomatology when Lyme patients are exposed to Babesia and Bartonella, and other sources of inflammation found on the 16-point MSIDS map. These may include genetic causes of autoimmunity, environmental toxins, nutritional deficiencies, food allergies/sensitivities, imbalances in the microbiome with or without leaky gut, ${ }^{137}$ and/or sleep disorders. These may all contribute to free radical/oxidative stress, further increasing inflammation and symptomatology with downstream effects. ${ }^{38-149}$

Chronic symptoms could therefore possibly overlap multifactorial causes on the MSIDS model. Fatigue for example could be due to infections, inflammation, autoimmunity, neuropsychiatric and/or sleep disorders, environmental toxins, mitochondrial dysfunction, nutritional deficiencies, food allergies/sensitivities, GI disorders and leaky gut, Hypothalamic-Pituitary-Adrenal (HPA) axis, autonomic nervous system dysfunction, as well as deconditioning; however these potential factors were often simultaneously or previously treated, and treating infections had significant positive effects. These factors will be discussed in detail in Precision Medicine: The Role of the MSIDS Model in Defining, Diagnosing and Treating Chronic Lyme Disease/PTLDS and Other Chronic Illness: Part 2. ${ }^{150}$

\section{Conclusion}

Many of our patients infected with Lyme disease and associated coinfections had severe symptoms, often relapsed with commonly used therapies, and did not present with an EM rash nor meet the CDC two-tiered surveillance criteria. Almost two-thirds of patients had been exposed to between five and eight infections/coinfections and $14.5 \%$ of patients were PCR positive for B. burgdorferi despite seemingly "adequate" antibiotic therapy for months or years prior to DDS therapy ( $\mathrm{N}=29,14.5 \%)$. Evidence of persistent infection with HHV6, Bartonella, and/or Mycoplasma was also confirmed by PCR in several patients, although many in our study had evidence of other medical problems accounting for ongoing symptoms. These included associated immune dysfunction/immune deficiency, inflammation, environmental toxins with detoxification problems, GI problems, allergies, nutritional deficiencies, hormone, and autonomic 
nervous system dysregulation as well as sleep and psychiatric disorders in those suffering with post treatment Lyme symptoms. ${ }^{151}$ None of these factors had been addressed in the three prior NIH randomized controlled Lyme trials ${ }^{6,152,153}$ nor the European PLEASE trial ${ }^{154}$ and could explain in part why patients remained ill. Many patients with late Lyme disease in those trials failed conventional beta lactam, tetracycline, macrolide, or other antibiotic therapies even if given for 4-6 weeks. These included those patients with evidence of carditis, arthritis, and neuroborreliosis, including but not limited to symptoms of diplopia (3rd and 4th cranial nerves [CN]), Bell's palsy (7th $\mathrm{CN}$ ), deafness (8th $\mathrm{CN})$, disequilibrium with ataxia (8th $\mathrm{CN})$, tongue palsy (12th $\mathrm{CN})$, dropped shoulder (11th $\mathrm{CN}$ ), and foot drop or leg paralysis (spinal cord involvement). Part II of this retrospective chart review will therefore address in detail the abnormalities found on the MSIDS map in those suffering with chronic Lyme disease/PTLDS, which could account for resistant, chronic symptomatology. MSIDS is a precision medical model that considers genetic, environmental, and lifestyle factors ${ }^{155}$ as well as individual differences in infectious burden, customizing and selecting appropriate and optimal therapies, tailoring and targeting treatments for individual differences. The goal of precision medicine is to address the individual needs of patients, improve clinical outcomes, and minimize side effects.

The rising numbers of individuals suffering with Lyme and other long-term disabling illnesses alert us to a necessary shift in the paradigm for the diagnosis and treatment of chronic disease ${ }^{149}$ and consideration of this precision medical approach. The MSIDS model and the use of persister drugs like DDS and pyrazinamide traditionally used for slow growing mycobacterial infections ${ }^{9}$ represent new effective therapeutic options in tick-borne disorders. Multi-drug therapies for extended duration have been used for successful eradication of Q-fever, ${ }^{156}$ mycobacterial diseases (ie, DDS with antituberculous drugs have been used effectively in leprosy regimens for half a century), as well as in other illnesses involving intracellular microorganisms like Brucella. ${ }^{157}$ DDS CT along with several agents that disrupt biofilms decreased the severity of eight major Lyme symptoms in our study in those with PTLDS/chronic Lyme disease, along with diagnosing and adequately treating multiple species of intracellular bacteria. Bartonella, Mycoplasma, rickettsia, tularemia, and Brucella along with parasitic infections like Babesia and viral infections including HHV-6 were all likely sources contributing to the burden of illness. In summary, DDS CT, along with identifying and treating tick-borne co-infections, and abnormalities on the MSIDS map all affected chronic symptomatology and provides an expanded medical resource for those failing traditional therapy.

\section{Acknowledgments}

We thank our Hudson Valley Healing Arts Center research team: Haley Moss Dillon, Sonja Siderias, Heather Orza, and Renee Nelson for their assistance, as well as Aron G Wiegand, Egamaria Alacam, and Connor Duncan who assisted us with data input. We acknowledge with thanks the Bay Area Lyme (BAL) Foundation and the MSIDS Research Foundation (MRF) for providing us research grants for the data mining portion of this study. Dr Richard I Horowitz would also like to express his appreciation to his colleagues and subcommittee members on the HHS Tick-Borne Disease Working Group for their dedication and expertise in the diagnosis and treatment of tick-borne disorders. The views expressed are those of Dr Richard I Horowitz and do not represent the views of the HHS Tick-Borne Disease Working Group. The funders had no role in the design of the study, in the collection, analyses, or interpretation of data, in the writing of the manuscript; and in the decision to publish the results.

\section{Disclosure}

The authors report no conflicts of interest in this work.

\section{References}

1. Kugeler KJ, Farley GM, Forrester JD, Mead PS. Geographic distribution and expansion of human Lyme disease, United States. Emerg Infect Dis. 2015;21(8):1455-1457.

2. How many people get Lyme disease? Lyme disease. CDC. Available from: https://www.cdc.gov/lyme/stats/humancases.html. Accessed February 13, 2018.

3. Rosenberg R, Lindsey NP, Fischer M, et al. Vital signs: trends in reported vectorborne disease cases - United States and Territories, 2004-2016. MMWR Morb Mortal Wkly Rep. 2018;67(17):496-501.

4. Record number of tickborne diseases reported in U.S. in 2017 CDC online newsroom. CDC. Available from: https://www.cdc.gov/ media/releases/2018/s1114-record-number-tickborne-diseases.html. Accessed December 19, 2018.

5. National Lyme STATs underestimate local cases. Available from: https://uw-media.poughkeepsiejournal.com/video/embed/94817864 ? sitelabel=reimagine \&continuousplay=true \&placement=uwsmallarticleattophtml $5 \&$ keywords $=$ pou-lyme-disease $\% 2 \mathrm{Cticks} \% 2 \mathrm{C}$ centers-for-disease-control-and-prevention $\% 2$ Clyme-disease $\% 2 \mathrm{Cep}$ idemiology $\% 2$ Chealth\&simpleTarget $=\&$ simpleExclusion=disasters \&pagetype=story. Accessed May 21, 2018.

6. Klempner MS, Hu LT, Evans J, et al. Two controlled trials of antibiotic treatment in patients with persistent symptoms and a history of Lyme disease. N Engl J Med. 2001;345(2):85-92.

7. Johnson L, Wilcox S, Mankoff J, Stricker RB. Severity of chronic Lyme disease compared to other chronic conditions: a quality of life survey. Peer J. 2014;2:e322.

8. I. Horowitz RIH, Freeman PR. The use of dapsone as a novel "persister" drug in the treatment of chronic Lyme disease/post treatment Lyme disease syndrome. J Clin Exp Dermatol Res. 2016;07(03):345. 
9. Zhang Y, Yew WW, Barer MR. Targeting persisters for tuberculosis control. Antimicrob Agents Chemother. 2012;56(5):2223-2230.

10. Barr J. A short history of dapsone, or an alternative model of drug development. J Hist Med Allied Sci. 2011;66(4):425-467.

11. Horowitz RI, Freeman P. The use of dapsone as a novel "persister" drug in the treatment of chronic Lyme disease/post treatment Lyme disease syndrome. J Clin Exp Dermatol Res. 2016;07(03):345.

12. WHO Model prescribing information: drugs used in leprosy. Available from: http://apps.who.int/medicinedocs/en/d/Jh2988e/. Accessed May 27, 2018.

13. Citera M, Freeman PR, Horowitz RI. Empirical validation of the Horowitz multiple systemic infectious disease syndrome questionnaire for suspected Lyme disease. Int J Gen Med. 2017;10:249-273.

14. Shadick NA, Phillips CB, Sangha O, et al. Musculoskeletal and neurologic outcomes in patients with previously treated Lyme disease. Ann Intern Med. 1999;131(12):919-926.

15. Ma B, Christen B, Leung D, Vigo-Pelfrey C. Serodiagnosis of Lyme borreliosis by western immunoblot: reactivity of various significant antibodies against Borrelia burgdorferi. J Clin Microbiol. 1992;30(2):370-376.

16. Fearnley A, Gupta K, Freeman PR, Horowitz RI. Effect of Dapsone and its Antimicrobial Combinations on Borrelia burgdorferi Biofilms. Presented at: the ILADS 16th Annual Meeting; 2016; Boston, MA.

17. Butler T. The Jarisch-Herxheimer reaction after antibiotic treatment of spirochetal infections: a review of recent cases and our understanding of pathogenesis. Am J Trop Med Hyg. 2017;96(1):46-52.

18. Kaplanski G, Granel B, Vaz T, Durand JM. Jarisch-Herxheimer reaction complicating the treatment of chronic $\mathrm{Q}$ fever endocarditis: elevated TNFalpha and IL-6 serum levels. J Infect. 1998;37(1):83-84.

19. Wajcman H, Galactéros F. Le déficit en glucose-6 phosphate déshydrogénase: protection contre le paludisme et risque d'accidents hémolytiques. Comptes Rendus Biologies. 2004;327(8):711-720.

20. Jopling WH. Side-effects of antileprosy drugs in common use. Lepr Rev. 1983;54(4):261-270.

21. Guragain S, Upadhayay N, Bhattarai BM. Adverse reactions in leprosy patients who underwent dapsone multidrug therapy: a retrospective study. Clin Pharmacol. 2017;9:73-78.

22. Morrison DB, Williams EF. Methemoglobin reduction by glutathione or cysteine. Science. 1938;87(2245):15-16.

23. Burke P, Jahangir K, Mr K, Kolber MR. Dapsone-induced methemoglobinemia. Can Fam Physician. 2013;59(9):958-961.

24. East J, Blanton LS. Symptomatic hyperbilirubinemia secondary to dapsone-induced hemolysis and atazanavir therapy. Antimicrob Agents Chemother. 2012;56(2):1081-1083.

25. Gilbert's syndrome - Symptoms and causes - Mayo Clinic. Available from: https://www.mayoclinic.org/diseases-conditions/gilbertssyndrome/symptoms-causes/syc-20372811. Accessed July 11, 2018.

26. Na X, Kelly C. Probiotics in Clostridium difficile infection. J Clin Gastroenterol. 2011;45(Suppl):S154-S158.

27. McFarland LV. Meta-analysis of probiotics for the prevention of antibiotic associated diarrhea and the treatment of Clostridium difficile disease. Am J Gastroenterol. 2006;101(4):812-822.

28. Lawley TD, Clare S, Walker AW, et al. Targeted restoration of the intestinal microbiota with a simple, defined bacteriotherapy resolves relapsing Clostridium difficile disease in mice. PLoS Pathog. 2012;8(10):e1002995.

29. Castagliuolo I, Riegler MF, Valenick L, Lamont JT, Pothoulakis C. Saccharomyces boulardii protease inhibits the effects of Clostridium difficile toxins A and B in human colonic mucosa. Infect Immun. 1999;67(1):302-307.

30. Prince HE, Lapé-Nixon M, Patel H, Yeh C. Comparison of the Babesia duncani (WA1) IgG detection rates among clinical sera submitted to a reference laboratory for WA1 IgG testing and blood donor specimens from diverse geographic areas of the United States. Clin Vaccine Immunol. 2010;17(11):1729-1733.
31. Direct diagnostic tests for Lyme disease. Clinical infectious diseases. Oxford Academic. Available from: https://academic.oup.com/cid/ advance-article/doi/10.1093/cid/ciy614/5126199. Accessed December 19, 2018.

32. The presenting manifestations of Lyme disease and the outcomes of treatment. NEJM. Available from: https://www.nejm.org/doi/ full/10.1056/NEJM200306123482423. Accessed July 25, 2018.

33. Tibbles CD, Edlow JA. Does this patient have erythema migrans? JAMA. 2007;297(23):2617-2627.

34. Strle F, Wormser GP, Mead P, et al. Gender disparity between cutaneous and non-cutaneous manifestations of Lyme borreliosis. PLoS One. 2013;8(5):e64110.

35. Stonehouse A, Studdiford JS, Henry CA. An update on the diagnosis and treatment of early Lyme disease: "focusing on the bull's eye, you may miss the mark". J Emerg Med. 2010;39(5):e147-e151.

36. Surveillance case definitions for current and historical conditions. NNDSS. Available from: https://wwwn.cdc.gov/nndss/conditions/. Accessed August 3, 2018.

37. Craft JE, Fischer DK, Shimamoto GT, Steere AC. Antigens of Borrelia burgdorferi recognized during Lyme disease. Appearance of a new immunoglobulin $\mathrm{M}$ response and expansion of the immunoglobulin $\mathrm{G}$ response late in the illness. J Clin Invest. 1986;78(4):934-939.

38. Embers ME, Hasenkampf NR, Jacobs MB, et al. Variable manifestations, diverse seroreactivity and post-treatment persistence in nonhuman primates exposed to Borrelia burgdorferi by tick feeding. PLoS One. 2017;12(12): $\mathrm{e} 0189071$.

39. Elsner RA, Hastey CJ, Olsen KJ, Baumgarth N. Suppression of longlived humoral immunity following Borrelia burgdorferi infection. PLoS Pathog. 2015;11(7):e1004976.

40. Marangoni A, Sparacino M, Mondardini V, et al. Comparative evaluation of two enzyme linked immunosorbent assay methods and three Western blot methods for the diagnosis of culture-confirmed early lyme borreliosis in Italy. New Microbiol. 2005;28(1):37-43.

41. Ang CW, Notermans DW, Hommes M, Simoons-Smit AM, Herremans T. Large differences between test strategies for the detection of antiBorrelia antibodies are revealed by comparing eight ELISAs and five immunoblots. Eur J Clin Microbiol Infect Dis. 2011;30(8):1027-1032.

42. Steere AC, Disease SL. Seronegative Lyme disease. JAMA. 1993;270(11):1369b.

43. Kaiser R. False-negative serology in patients with neuroborreliosis and the value of employing of different borrelial strains in serological assays. J Med Microbiol. 2000;49(10):911-915.

44. Brunner M. New method for detection of Borrelia burgdorferi antigen complexed to antibody in seronegative Lyme disease. J Immunol Methods. 2001;249(1-2):185-190.

45. Dejmková H, Hulínska D, Tegzová D, Pavelka K, Gatterová J, Vavrík P. Seronegative Lyme arthritis caused by Borrelia garinii. Clin Rheumatol. 2002;21(4):330-334.

46. Breier F, Khanakah G, Stanek G, et al. Isolation and polymerase chain reaction typing of Borrelia afzelii from a skin lesion in a seronegative patient with generalized ulcerating bullous lichen sclerosus et atrophicus. Br J Dermatol. 2001;144(2):387-392.

47. Schutzer SE, Coyle PK, Belman AL, Golightly MG, Drulle J. Sequestration of antibody to Borrelia burgdorferi in immune complexes in seronegative Lyme disease. The Lancet. 1990;335(8685):312-315.

48. Cook M, Puri B. Commercial test kits for detection of Lyme borreliosis: a meta-analysis of test accuracy. Int J Gen Med. 2016;9:427-440.

49. Cook M, Puri B. Application of Bayesian decision-making to laboratory testing for Lyme disease and comparison with testing for HIV. Int J Gen Med. 2017;10:113-123.

50. Dattwyler RJ, Volkman DJ, Luft BJ, et al. Dissociation of specific Tand B-lymphocyte responses to Borrelia burgdorferi. $N$ Engl J Med. 1988;319(22):1441-1446.

51. Pikelj F, Strle F, Mozina M. Seronegative Lyme disease and transitory atrioventricular block. Ann Intern Med. 1989;111(1):90. 
52. Leeflang MMG, Ang CW, Berkhout J, et al. The diagnostic accuracy of serological tests for Lyme borreliosis in Europe: a systematic review and meta-analysis. BMC Infectious Diseases. 2016;16(1):140.

53. Office of HIV/AIDS and Infectious Disease Policy AS for H (ASH). Report of Other TBDS and Co-Infections Subcommittee; May 9 , 2018. HHS.gov. Available from: https://www.hhs.gov/ash/advisorycommittees/tickbornedisease/reports/other-tbds-2018-5-9/index.html. Accessed May 21, 2018.

54. Branda JA, Linskey K, Kim YA, Steere AC, Ferraro MJ. Two-tiered antibody testing for Lyme disease with use of 2 enzyme immunoassays, a whole-cell sonicate enzyme immunoassay followed by a VlsE C6 peptide enzyme immunoassay. Clin Infect Dis. 2011;53(6):541-547.

55. Rudenko N, Golovchenko M, Grubhoffer L, Oliver JH. Updates on Borrelia burgdorferi sensu lato complex with respect to public health. Ticks Tick Borne Dis. 2011;2(3):123-128.

56. Roscoe C, Epperly T. Tick-borne relapsing fever. Am Fam Physician. 2005;72(10):2039-2044.

57. Porwancher R. A reanalysis of IgM Western blot criteria for the diagnosis of early Lyme disease. J Infect Dis. 1999;179(4):1021-1024.

58. Arnaboldi PM, Dattwyler RJ. Cross-reactive epitopes in Borrelia burgdorferi p66. Clin Vaccine Immunol. 2015;22(7):840-843.

59. Bruckbauer HR, Preac-Mursic V, Fuchs R, Wilske B. Cross-reactive proteins of Borrelia burgdorferi. Eur J Clin Microbiol Infect Dis. 1992;11(3):224-232.

60. Krause PJ, Carroll M, Fedorova N, et al. Human Borrelia miyamotoi infection in California: serodiagnosis is complicated by multiple endemic Borrelia species. PLoS One. 2018;13(2):e0191725.

61. Strobino B, Steinhagen K, Meyer W, et al. A community study of Borrelia burgdorferi antibodies among individuals with prior Lyme disease in endemic areas. Healthcare. 2018;6(2):69.

62. Horowitz RI. Approach to diagnosing Lyme disease misses a large proportion of cases. BMJ. 2016;352:i113.

63. Branda JA, Rosenberg ES. Borrelia miyamotoi: a lesson in disease discovery. Ann Intern Med. 2013;159(1):61.

64. Rudenko N, Golovchenko M, Vancova M, Clark K, Grubhoffer L, Oliver $\mathrm{JH}$. Isolation of live Borrelia burgdorferi sensu lato spirochaetes from patients with undefined disorders and symptoms not typical for Lyme borreliosis. Clin Microbiol Infect. 2016;22(3):267:267.e9.

65. Nieto NC, Porter WT, Wachara JC, et al. Using citizen science to describe the prevalence and distribution of tick bite and exposure to tickborne diseases in the United States. PLoS One. 2018;13(7):e0199644.

66. Baranton G, Postic D, Saint Girons I, Girons S I, et al. Delineation of Borrelia burgdorferi sensu stricto, Borrelia garinii sp. nov., and group VS461 associated with Lyme borreliosis. Int J Syst Bacteriol. 1992;42(3):378-383.

67. Hauser U, Lehnert G, Lobentanzer R, Wilske B. Interpretation criteria for standardized Western blots for three European species of Borrelia burgdorferi sensu lato. J Clin Microbiol. 1997;35(6):1433-1444.

68. Improved Sensitivity of Lyme disease Western Blots Prepared with a Mixture of Borrelia Burgdorferi Strains 297 and B31. Available from: http://austinpublishinggroup.com/chronic-diseases/fulltext/ chronicdiseases-v1-id1009.php. Accessed December 19, 2018.

69. Liu S, Cruz I, Ramos C, Taleon P, Ramasamy R, Shah J. Pilot study of immunoblots with recombinant Borrelia burgdorferi antigens for laboratory diagnosis of Lyme disease. Healthcare. 2018;6(3):99.

70. Woodman ME, Cooley AE, Stevenson B. Production of outer surface protein A by Borrelia burgdorferi during transmission from infected mammals to feeding ticks is insufficient to trigger OspA seroconversion. FEMS Immunol Med Microbiol. 2008;54(2):277-282.

71. Strother KO, Hodzic E, Barthold SW, de Silva AM. Infection of mice with Lyme disease spirochetes constitutively producing outer surface proteins A and B. Infect Immun. 2007;75(6):2786-2794.

72. Akin E, Mchugh GL, Flavell RA, Fikrig E, Steere AC. The immunoglobulin (IgG) antibody response to OspA and OspB correlates with severe and prolonged Lyme arthritis and the IgG response to P35 correlates with mild and brief arthritis. Infect Immun . 1999;67(1):173-181.
73. Alaedini A, Latov N. Antibodies against OspA epitopes of Borrelia burgdorferi cross-react with neural tissue. J Neuroimmunol. 2005;159(1-2):192-195.

74. Tijsse-Klasen E, Pandak N, Hengeveld P, Takumi K, Koopmans MPG, Sprong H. Ability to cause erythema migrans differs between Borrelia burgdorferi sensu lato isolates. Parasit Vectors. 2013;6(1):23.

75. Mozayeni BR, Maggi RG, Bradley JM, Breitschwerdt EB. Rheumatological presentation of Bartonella koehlerae and Bartonella henselae bacteremias. Medicine. 2018;97(17):e0465.

76. Office of HIV/AIDS and Infectious Disease Policy AS for H (ASH). Report of Other TBDS and Co-Infections Subcommittee; May 9, 2018. Available from: https://www.hhs.gov/ash/advisory-committees/ tickbornedisease/reports/other-tbds-2018-5-9/index.html. Accessed May 21, 2018.

77. Goethert HK, Molloy P, Berardi V, Weeks K, Telford SR, Srt I. Zoonotic Babesia microti in the northeastern U.S.: evidence for the expansion of a specific parasite lineage. PLoS One. 2018;13(3):e0193837.

78. Scott J, Scott C. Human babesiosis caused by Babesia duncani has widespread distribution across Canada. Healthcare. 2018;6(2):49.

79. Scott JD, La D, Durden LA. Amblyomma dissimile Koch (Acari: Ixodidae) parasitizes bird captured in Canada. Systematic and Applied Acarology. 2015;20(8):854-860.

80. Scott JD. First record of locally acquired human babesiosis in Canada caused by Babesia duncani: a case report. SAGE Open Med Case Rep. 2017;5:2050313X1772564.

81. Hamer SA, Goldberg TL, Kitron UD, et al. Wild birds and urban ecology of ticks and tick-borne pathogens, Chicago, Illinois, USA, 2005-2010. Emerg. Infect. Dis. . 2012;18(10):1589-1595.

82. Elfving K, Olsen B, Bergstrom S. Dissemination of spotted fever Rickettsia agents in Europe by migrating birds. 2018. Available from: http:// journals.plos.org/plosone/article?id=10.1371/journal.pone.0008572. Accessed July 6.

83. Mascarelli PE, Mcquillan M, Harms C, Harms R, Breitschwerdt E. Bartonella henselae and B. koehlerae DNA in birds. Emerg Infect Dis. 2014;20:491-492.

84. Newman EA, Eisen L, Eisen RJ, et al. Borrelia burgdorferi sensu lato spirochetes in wild birds in northwestern California: associations with ecological factors, bird behavior and tick infestation. Plos One. 2015;10(2):e0118146.

85. Girard YA, Fedorova N, Lane RS. Genetic diversity of Borrelia burgdorferi and detection of B. bissettii-like DNA in serum of north-coastal California residents. J Clin Microbiol. 2011;49(3):945-954.

86. Asian ticks (mysteriously) turned up on a New Jersey sheep. NPR.org. Available from: https://www.npr.org/sections/goatsandsoda/2018/02/27/588408433/asian-ticks-mysteriously-turned-up-ona-new-jersey-sheep. Accessed July 6, 2018.

87. Rosenbaum L. This invasive tick can clone itself and suck livestock dry. Science News. Available from: https://www.sciencenews.org/ article/invasive-longhorned-tick-can-clone-itself-suck-livestock-dry. Published June 29, 2018. Accessed July 6, 2018.

88. WCSU confirms first specimen of new tick in Connecticut NewsTimes. Available from: https://www.newstimes.com/local/ article/WCSU-confirms-first-specimen-of-new-tick-in-13193573.php. Accessed September 3, 2018.

89. Chinuki Y, Ishiwata K, Yamaji K, Takahashi H, Morita E. Haemaphysalis longicornis tick bites are a possible cause of red meat allergy in Japan. Allergy. 2016;71(3):421-425.

90. Commins SP, Platts-Mills TA. Tick bites and red meat allergy. Curr Opin Allergy Clin Immunol. 2013;13(4):354-359.

91. Thomm AM, Schotthoefer AM, Dupuis AP, et al. Development and validation of a serologic test panel for detection of Powassan virus infection in U.S. patients residing in regions where Lyme disease is endemic. mSphere. 2018;3(1):e0467-17.

92. Tokarz R, Sameroff S, Tagliafierro T, et al. Identification of Novel Viruses in Amblyomma americanum, Dermacentor variabilis, and Ixodes scapularis Ticks. mSphere. 2018;3(2):e00614-17. 
93. Moritz ED, Winton CS, Tonnetti L, et al. Screening for Babesia microti in the U.S. Blood Supply. N Engl J Med. 2016;375(23):2236-2245.

94. Feder HM, Lawlor M, Krause PJ. Babesiosis in pregnancy. New Engl J Med. 2003;349(2):195-196.

95. Hersh MH, Ostfeld RS, Mchenry DJ, et al. Co-infection of Blacklegged ticks with Babesia microti and Borrelia burgdorferi is higher than expected and acquired from small mammal hosts. PLoS ONE. 2014;9(6):e99348.

96. Saetre K, Godhwani N, Maria M, et al. Congenital babesiosis after maternal infection with Borrelia burgdorferi and Babesia microti. J Pediatric Infect Dis Soc. 2018;7(1):e1-e5.

97. Krause PJ, Gewurz BE, Hill D, et al. Persistent and relapsing babesiosis in immunocompromised patients. Clin Infect Dis. 2008;46(3):370-376.

98. Sethi S, Alcid D, Kesarwala H, Tolan RW. Probable congenital babesiosis in infant, New Jersey, USA. Emerg Infect Dis. 2009;15(5):788-791.

99. Anderson A, Bijlmer H, Fournier P.-E. Diagnosis and management of Q fever - United States; 2013. Available from: https://www.cdc.gov/ $\mathrm{mmwr} / \mathrm{preview} / \mathrm{mmwrhtml} / \mathrm{rr} 6203 \mathrm{a} 1 \mathrm{htm}$. Accessed May 21, 2018.

100. Chowdri HR, Gugliotta JL, Berardi VP, et al. Borrelia miyamotoi Infection Presenting as Human Granulocytic Anaplasmosis. Ann Intern Med. 2013;159(1):21-27.

101. Krause PJ, Telford SR, Spielman A, et al. Concurrent Lyme disease and babesiosis. Evidence for increased severity and duration of illness. JAMA. 1996;275(21):1657-1660.

102. Mylonakis E, Eleftherios M. When to suspect and how to monitor babesiosis. Am Fam Physician. 2001;63(10):1969-1975.

103. Investigating disease severity in an animal model of concurrent babesiosis and Lyme disease. Available from: https://www.ncbi.nlm.nih. gov/pubmed/30367867. Accessed December 19, 2018.

104. Horowitz ML, Coletta F, Fein AM. Delayed onset adult respiratory distress syndrome in babesiosis. Chest. 1994;106(4):1299-1301.

105. Knapp KL, Rice NA. Human coinfection with Borrelia burgdorferi and Babesia microti in the United States. J Parasitol Res. 2015;2015:1-11.

106. Wilson M, Glaser KC, Adams-Fish D, Boley M, Mayda M, Molestina RE. Development of droplet digital PCR for the detection of Babesia microti and Babesia duncani. Exp Parasitol. 2015;149:24-31.

107. Shah J, Mark O, Weltman H, et al. Fluorescence in situ hybridization (fish) assays for diagnosing malaria in endemic areas. PLoS One. 2015;10:9.

108. Lempereur L, Shiels B, Heyman P, et al. A retrospective serological survey on human babesiosis in Belgium. Clin Microbiol Infect. 2015;21(1):96:96.e1.

109. Eskow E, Rao RV, Mordechai E. Concurrent infection of the central nervous system by Borrelia burgdorferi and Bartonella henselae: evidence for a novel tick-borne disease complex. Arch Neurol. 2001;58(9):1357-1363.

110. Pérez-Castrillón JL, Bachiller-Luque P, Martín-Luquero M, MenaMartín FJ, Herreros V. Tularemia epidemic in northwestern Spain: Clinical description and therapeutic response. Clin Infect Dis. 2001;33(4):573-576.

111. Nicolson GL, Gan R, Haier J. Multiple co-infections (Mycoplasma, Chlamydia, human herpes virus-6) in blood of chronic fatigue syndrome patients: association with signs and symptoms. APMIS. 2003;111(5):557-566.

112. Horowitz R.I, Freeman P.R. Are Mycobacterium drugs effective for treatment resistant Lyme disease, Tick- borne co-infections, and autoimmune disease? ResearchGate. Available from: https://www. researchgate.net/publication/314217187_Are_Mycobacterium_Drugs_ Effective_for_Treatment_Resistant_Lyme_Disease_Tick-_Borne_CoInfections_and_Autoimmune_Disease. Accessed February 5, 2018.

113. Nicolson GL, Nicolson NL, Haier J. Chronic fatigue syndrome patients subsequently diagnosed with lyme disease Borrelia burgdorferi : evidence for Mycoplasma species coinfections. Journal of Chronic Fatigue Syndrome. 2007;14(4):5-17.

114. Eskow E, Adelson ME, Rao RV, Mordechai E. Evidence for disseminated Mycoplasma fermentans in New Jersey residents with antecedent tick attachment and subsequent musculoskeletal symptoms. J Clin Rheumatol. 2003;9(2):77-87.
115. Benedetti F. Placebo and the new physiology of the doctor-patient relationship. Physiol Rev. 2013;93(3):1207-1246.

116. Castelnuovo G, Giusti EM, Manzoni GM, et al. What is the role of the placebo effect for pain relief in neurorehabilitation? Clinical implications from the Italian consensus Conference on pain in neurorehabilitation. Front Neurol. 2018;9:310.

117. Minnick MF, Battisti JM, Pestilence BJM. Pestilence, persistence and pathogenicity: infection strategies of Bartonella. Future Microbiol. 2009;4(6):743-758.

118. Maggi RG, Mascarelli PE, Havenga LN, Naidoo V, Breitschwerdt EB. Co-infection with Anaplasma platys, Bartonella henselae and Candidatus Mycoplasma haematoparvum in a veterinarian. Parasit Vectors. 2013;6:103.

119. Allred DR. Babesiosis: persistence in the face of adversity. Trends Parasitol. 2003;19(2):51-55.

120. Krause PJ, Spielman A, Telford SR, et al. Persistent parasitemia after acute babesiosis. N Engl J Med. 1998;339(3):160-165.

121. Rudenko N, Golovchenko M, Vancova M, Clark K, Grubhoffer L, Oliver $\mathrm{JH}$. Isolation of live Borrelia burgdorferi sensu lato spirochaetes from patients with undefined disorders and symptoms not typical for Lyme borreliosis. Clin Microbiol Infect. 2016;22(3):267:267.e9.

122. Lee SH, Vigliotti JS, Vigliotti VS, Jones W, Moorcroft TA, Lantsman $\mathrm{K}$. DNA sequencing diagnosis of off-season spirochetemia with low bacterial density in Borrelia burgdorferi and Borrelia miyamotoi infections. Int J Mol Sci. 2014;15(7):11364-11386.

123. Lee SH, Vigliotti JS, Vigliotti VS, Jones W, Shearer DM. Detection of borreliae in archived sera from patients with clinically suspect Lyme disease. Int J Mol Sci. 2014;15(3):4284-4298.

124. Ericson M, Balakrishnan N, Mozayeni BR, Br M, et al. Culture, PCR, DNA sequencing, and second harmonic generation (SHG) visualization of Bartonella henselae from a surgically excised human femoral head. Clin Rheumatol. 2017;36(7):1669-1675.

125. Harms A, Dehio C. Intruders below the radar: molecular pathogenesis of Bartonella spp. Clin Microbiol Rev. 2012;25(1):42-78.

126. Finlay BB, Mcfadden G. Anti-Immunology: evasion of the host immune system by bacterial and viral pathogens. Cell. 2006;124(4): 767-782.

127. Nicolson GL. Chronic bacterial and viral infections in neurodegenerative and neurobehavioral diseases. Lab Med. 2008;39(5):291-299.

128. Horowitz RI, Horowitz RI. 2003. Mycoplasma Infections in Chronic Lyme Disease: A Retrospective Analysis of Co-Infection and Persistence Demonstrated by PCR Analysis Despite Long Term Antibiotic Treatment [Abstract]. Presented at: 16th International Scientific Conference on Lyme \& Other Tick-Borne Disorders; 2003; Hartford CT.

129. Horowitz RI. Chronic Persistent Babesiosis after Clindamycin and Quinine/Mepron and Zithromax. [Abstract]. 12th International Conference on Lyme Borreliosis. Presented at: 12th International Conference on Lyme Borreliosis; April 1999; New York, NY.

130. Wormser GP, Prasad A, Neuhaus E, et al. Emergence of resistance to azithromycin-atovaquone in immunocompromised patients with Babesia microti infection. Clin Infect Dis. 2010;50(3):381-386.

131. Lemieux JE, Tran AD, Freimark L, et al. A global map of genetic diversity in Babesia microti reveals strong population structure and identifies variants associated with clinical relapse. Nat Microbiol. 2016;1(7):16079.

132. Sánchez-Vargas FM, Gómez-Duarte OG. Mycoplasma pneumoniaean emerging extra-pulmonary pathogen. Clin Microbiol Infect. 2008;14(2):105-115.

133. Donta ST. Macrolide therapy of chronic Lyme disease. Med Sci Monit. 2003;9(11):PI136-142.

134. Brorson O, Brorson SH. An in vitro study of the susceptibility of mobile and cystic forms of Borrelia burgdorferi to hydroxychloroquine. Int Microbiol. 2002;5(1):25-31.

135. Goc A, Rath M, Donta ST. The anti-borreliae efficacy of phytochemicals and micronutrients: an update. Ther Adv Infect Dis. 2016;3(3-4):75-82. 
136. Feng J, Zhang S, Shi W, Zubcevik N, Miklossy J, Zhang Y. Selective essential oils from spice or culinary herbs have high activity against stationary phase and biofilm Borrelia burgdorferi. Front Med. 2017;4:169.

137. Lerner A, Matthias T. Changes in intestinal tight junction permeability associated with industrial food additives explain the rising incidence of autoimmune disease. Autoimmun Rev. 2015;14(6):479-489.

138. Moutailler S, Valiente Moro C, Vaumourin E, et al. Co-infection of ticks: the rule rather than the exception. PLoS Negl Trop Dis. 2016;10(3):e0004539.

139. Nelder MP, Russell CB, Sheehan NJ, et al. Human pathogens associated with the blacklegged tick Ixodes scapularis: a systematic review. Parasit Vectors. 2016;9:265.

140. Breitschwerdt EB. Bartonellosis: one health perspectives for an emerging infectious disease. Ilar J. 2014;55(1):46-58.

141. Breitschwerdt EB. Bartonellosis, one health and all creatures great and small. Vet Dermatol. 2017;28(1):96-e21.

142. Nicolson G, Haier J. Role of chronic bacterial and viral infections in neurodegenerative, neurobehavioural, psychiatric, autoimmune and fatiguing illnesses: Part 2. Br J Med Pract. 2010;2010(3):301-310.

143. Simecka JW, Ross SE, Cassell GH, Davis JK. Interactions of mycoplasmas with B cells: antibody production and nonspecific effects. Clin Infect Dis. 1993;17(Suppl 1):S176-S182.

144. Furr PM, Taylor-Robinson D, Webster AD. Mycoplasmas and ureaplasmas in patients with hypogammaglobulinaemia and their role in arthritis: microbiological observations over twenty years. Ann Rheum Dis. 1994;53(3):183-187.

145. Chen W, Li D, Paulus B, Wilson I, Chadwick VS. High prevalence of Mycoplasma pneumoniae in intestinal mucosal biopsies from patients with inflammatory bowel disease and controls. Dig Dis Sci. 2001;46(11):2529-2535.

146. Maeda Y, Kurakawa T, Umemoto E, et al. Dysbiosis contributes to arthritis development via activation of autoreactive $\mathrm{T}$ cells in the intestine. Arthritis Rheumatol. 2016;68(11):2646-2661.
147. Parks CG, Miller FW, Pollard KM, Km P, et al. Expert panel Workshop consensus statement on the role of the environment in the development of autoimmune disease. Int $\mathrm{J} \mathrm{Mol} \mathrm{Sci}$. 2014;15(8):14269-14297.

148. Jomova K, Vondrakova D, Lawson M, Valko M, Metals VM. Metals, oxidative stress and neurodegenerative disorders. Mol Cell Biochem. 2010;345(1-2):91-104.

149. Horowitz RI. Clinical roundup: selected treatment options for Lyme disease. Altern Complement Ther. 2012;18(4):220-225.

150. Horowitz RI, Freeman PR. Precision medicine: the role of the MSIDS model in defining, diagnosing, and treating chronic Lyme Disease/Post treatment Lyme disease syndrome and other chronic illness: Part 2. Healthcare. 2018;6(4):129.

151. Doshi S, Keilp JG, Strobino B, Mcelhiney M, Rabkin J, Fallon BA. Depressive symptoms and suicidal ideation among symptomatic patients with a history of Lyme disease vs two comparison groups. Psychosomatics. 2018;59(5):481-489.

152. Krupp LB, Hyman LG, Grimson R, et al. Study and treatment of post Lyme disease (STOP-LD): a randomized double masked clinical trial. Neurology. 2003;60(12):1923-1930.

153. Fallon BA, Keilp JG, Corbera KM, Ba F, Km C, et al. A randomized, placebo-controlled trial of repeated IV antibiotic therapy for Lyme encephalopathy. Neurology. 2008;70(13):992-1003.

154. Berende A, Ter Hofstede HJ, Vos FJ, Hofstede Hjm TER, et al. Randomized trial of longer-term therapy for symptoms attributed to Lyme disease. N Engl J Med. 2016;374(13):1209-1220.

155. Larry Jameson J, Longo DL, Medicine - personalized P. Problematic, and promising. Obstetrical \& Gynecological Survey. 2015;70(10):612.

156. Kersh GJ. Antimicrobial therapies for Q fever. Expert Rev Anti Infect Ther. 2013;11(11):1207-1214.

157. Alavi SM, Alavi L. Treatment of brucellosis: a systematic review of studies in recent twenty years. Caspian J Intern Med. 2013;4(2): 636-641.
International Journal of General Medicine

\section{Publish your work in this journal}

The International Journal of General Medicine is an international, peer-reviewed open-access journal that focuses on general and internal medicine, pathogenesis, epidemiology, diagnosis, monitoring and treatment protocols. The journal is characterized by the rapid reporting of reviews, original research and clinical studies across all disease areas.

\section{Dovepress}

The manuscript management system is completely online and includes a very quick and fair peer-review system, which is all easy to use. Visit http://www.dovepress.com/testimonials.php to read real quotes from published authors. 